\title{
EFFECTS OF EXPERIENTIAL FOCUSING-ORIENTED \\ DREAM INTERPRETATION
}

\section{DISSERTATION}

\author{
Presented to the Graduate Council of the \\ University of North Texas in Partial \\ Fulfillment of the Requirements
}

For the Degree of

DOCTOR OF PHILOSOPHY

By

Kuei-an Kan, B.Ed., M.Ed.

Denton, Texas

August, 1998 


\section{$g^{m+1}$}

Kan, Kuei-an, Effects of Experiential FocusingOriented Dream Interpretation, Doctor of Philosophy (Counseling and Student Services), August, 1998, $170 \mathrm{pp}$. 13 tables, references, 78 titles.

This study was designed to examine the effects of Experiential Focusing-oriented dream interpretation. The process was twofold. The first part of this study involved a preliminary step of developing an instrument, the Dream Interpretation Effects Questionnaire (DIEQ). The DIEQ assessed specific effects of Experiential Focusing-oriented dream interpretation, e.g., a sense of easing, fresh air, or movement, increased positive energy or selfunderstanding, development of a new step, enhanced valuation of dreams, or enhanced understanding of the meaning of the dream. Fifty-two adult volunteers participated in the first part of this study. All participants completed Part One of the DIEQ after reporting a dream and freely associating its meaning to another participant. The results were computed to establish the reliability of the DIEQ.

The researcher then used the DIEQ along with a 
structured interview in a pretest-posttest control group design to examine the effects of Experiential Focusingoriented dream interpretation. Twenty adult volunteers experienced in Experiential Focusing participated in the second part of this study. They were randomly assigned to an experimental group and a waiting-list control group. The experimental participants completed the DIEQ before (pretest) and after (posttest) a 45-minute Experiential Focusing-oriented dream interpretation intervention. By contrast, the control participants completed the DIEQ before (pretest) and after (first posttest) a 45-minute nointervention waiting period. Then, the control group participants received the same intervention as the experimental group and completed the DIEQ (second posttest). All participants participated in a structured interview to conclude the study.

The results of this study illustrated various aspects of the effects of Experiential Focusing-oriented dream interpretation. For the first part, the DIEQ proved to be highly reliable. For the second part, Experiential Focusing-oriented dream interpretation showed significant results. This study offers support to Gendlin's assertion that an Experiential Focusing approach to dream 
interpretation makes use of the organismic inner knowing implied in the felt sense of a dream and facilitates psychological change for the dreamer. 


\title{
EFFECTS OF EXPERIENTIAL FOCUSING-ORIENTED \\ DREAM INTERPRETATION
}

\section{DISSERTATION}

\author{
Presented to the Graduate Council of the \\ University of North Texas in Partial \\ Fulfillment of the Requirements
}

For the Degree of

DOCTOR OF PHILOSOPHY

By

Kuei-an Kan, B.Ed., M.Ed.

Denton, Texas

August, 1998 
Copyright by

Kuei-an Kan

1998 
TABLE OF CONTENTS

Page

LIST OF TABLES.......................

Chapter

I. INTRODUCTION. .....................

Purpose of the study

Synthesis of Related Literature

Experiential Focusing

Client-Centered Therapy and the Emergence of Experiential Psychotherapy

Content and Process of Experiential Focusing

Felt Sense and Focusing Attitude

Healing Force Implicit in the Felt Sense

The Procedure of Experiential Focusing

Research Related to Experiential Focusing

Dreams and Dream Interpretation

Types of Dreams

Theories of Dreaming

Approaches to Dream Interpretation

Research on Dreams and Psychotherapy

Research on Dream Interpretation

Research on Experiencing Level and Dreams

Summary

II. METHODOLOGY .....................

First Part of the study: Development of Part One of the Dream Interpretation Effects Questionnaire Research Hypothesis 1

Development of Instrument Items

Selection of Participants

Procedures

Limitations

Collection of Data

Analysis of Data 
Second Part of the Study: Effects of Focusing-

Oriented Dream Interpretation

Research Hypotheses 2-5

Research Question

Definition of Terms

Selection of Participants

Intervention

Instrumentation

Research Design and Procedures

Limitations

Collection of Data

Analysis of Data

III. RESULTS AND DISCUSSION.................96

Results

Discussion

Summary of Recommendations

Conclusion

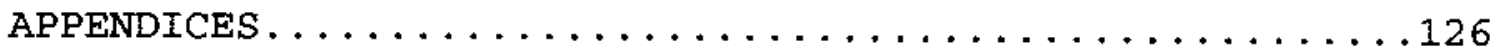

A. The Informed Consent Form for the First Part of the Study

B. The Informed Consent Form for the second Part of the Study

C. Major Effects of Focusing-Oriented Dream

Interpretation

D. Random Item Assignment for Part one Pilot Form

E. Pilot Part One of the Dream Interpretation Effects Questionnaire

F. The Dream Interpretation Effects Questionnaire

G. Structured Interview

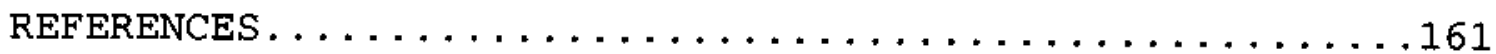




\section{LIST OF TABLES}

Table

Page

1. Reliability Analysis of the DIEQ .............97

2. T-test of Pretest and Posttest DIEQ Scores for

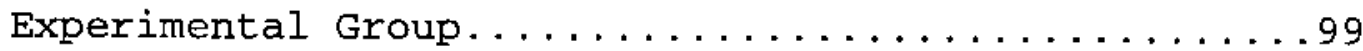

3. T-test of Pretest and First Postest DIEQ Scores for Control Group........................ 100

4. T-test of Difference Between Pretest and Posttest DIEQ Scores for Experimental and Control Group.....101

5. T-test of First Posttest and Second Posttest DIEQ Scores for Control Group..................... 102

6. Background Information of the Research Participants.......................... 104

7. Mean Scores and Test Statistic for Major Effect (1) A Sense of Easing or Release of Tension

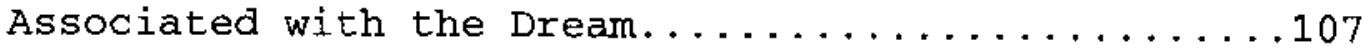

8. Mean Scores and Test Statistic for Major Effect (2) A Sense of Fresh Air or Increase of Positive Energy Associated with the Dream..............108

9. Mean Scores and Test Statistic for Major Effect (3) Increased of Self Understanding..............109

10. Mean Scores and Test Statistic for Major Effect (4) A Sense of Movement, Reconciliation, or Healing.............................. 110

11. Mean Scores and Test Statistic for Major Effect (5) Development of a New Step or New Direction Regarding a Concern..................... 112 
12. Mean Scores and Test Statistic for Major Effect (6) Enhanced Valuation of Dreams..............113

13. Mean Scores and Test Statistic for Major Effect (7) Enhanced Understanding of the Meaning of the Dream..............................115 
CHAPTER I

INTRODUCTION

In the early 1960's Eugene Gendlin and his colleagues studied tapes of therapy sessions to determine if there was a difference between successful and unsuccessful therapy sessions. They discovered that the successful therapy clients spent time attending to their bodily felt sense of a concern during the session (Gendlin, 1974). Gendlin developed a procedure, which he called "Focusing," to teach what the successful clients were doing in the therapy sessions (Gendlin, 1969, 1981). Since then, professionals as well as non-professionals have used focusing to facilitate personal change.

Findings in dream research have indicated that the human mind is never entirely at rest during sleep. Some form of mental activity, which takes the form of dreams, goes on throughout the night (Faraday, 1972; Foulkes \& Vogel, 1965; Foulkes \& Fleischer, 1975; Hobson, 1989; Moffitt, Kramer, \& Hoffmann, 1993; Strauch \& Meier, 1996). Scientists and psychologists have presented antagonistic 
viewpoints about dreams. However, observations made from research studies and clinical experiences have suggested that areams have both physiological and psychological functions (Hunt, 1989; Stevens, 1995). States (1992) proposed a phenomenological approach to the meaning of dreams. He suggested that the meaning of dreams lies in the interpretation rather than in the dream itself.

Gendlin (1986) suggested that dreams are invaluable vehicles for change. He proposed two very important functions of areams: 1) dreams bring into awareness unconscious material that is ready to be worked with by the dreamer, and 2) a dream's version of a concern implies "clues to and energy for the steps to a solution" (Gendlin, 1996, p. 200). He (1986) developed a Focusing approach to dream interpretation. The unique characteristic of his approach is that it uses all other psychotherapeutic approaches to dream interpretation with the added component of anchoring the approach in the experiential felt sense of the individual. He believed that only the dreamer's body holds the key to the true meaning of a dream.

In contrast to the countless writings and interest in dreams, only a few empirical studies have been conducted on dream interpretation, among which none has been conducted 
on Focusing-oriented dream interpretation. Existing dream interpretation research findings offer some support for the efficacy of dream interpretation. However, many have suggested that valid and reliable assessment instruments and more empirical studies are needed to answer the many untested hypotheses in the theory and clinical practice of dream interpretation (Cogar \& Hill, 1992; Falk \& Hill, 1995; Hi11, Diemer, Hess, Hillyer, \& Seeman, 1993). Purpose of the Study

The general purpose of this study can be described as an intermediate information gathering step regarding the effects of Experiential Focusing-oriented dream interpretation. The emphasis was on gathering new information based on what is already known. The process involved two different parts. The first part reviewed the existing Iiterature's account of the possible effects of Experiential Focusing-oriented dream interpretation, and a preliminary instrument was developed based on the result. By contrast, the second part used the instrument developed in the first part, in an experimental-control group design to examine each experimental participant's actual experience and selfureport of the effects of Experiential Focusing-oriented dream interpretation. In other words, the 
first part of this study involved a preliminary step of using existing dream interpretation literature to develop an instrument that is sensitive to the specific effects of Experiential Focusing-oriented dream interpretation. The second part of this study used the instrument in a pretestposttest control group design along with a variety of qualitative methods to examine the effects of Experiential Focusing-oriented dream interpretation.

In summary, the specific purpose of this study was to develop and use an assessment instrument to examine the effects of Experiential Focusing-oriented dream interpretation on selected categories of major subjective outcomes of dream interpretation. The basic assumption of this study was that anyone can use an inherent organismic inner knowing for personal development. From this perspective, one way an individual can exploit this source of personal development is to use a technique that facilitates psychological change, Experiential Focusing, to examine personal material that is readily accessible on a daily basis, dreams.

The participants in the first part of this study were volunteer graduate students. The participants of the second part of this study were individuals who had no specific 
presenting problem but who were open to work with any issue as revealed or presented by their dreams and who had experience with Focusing. The material for study was nighttime dreams that are available to most people if remembered. The tool that was used to work with the dream material was Experiential Focusing, a technique that facilitates psychological change. Experiential Focusingoriented dream interpretation emphasizes using one's own inner authority and inner knowing to interpret one's dreams. It is a tool that anybody can learn to use by oneself or with a partner. The research design used in this study was a pretest-posttest control group design. Both quantitative and qualitative data were gathered to examine the effects of Experiential Focusing-oriented dream interpretation on participants' processing and interpretation of their dreams.

Synthesis of Related Ijterature

Experiential Focusing

Experiential Focusing evolved from Carl Rogers' client-centered therapy. In his efforts to experimentally study human change, Rogers began to shift from holding a static view of personality to appreciating a process view of human nature (Rogers, 1958). At the same time, 
psychologist Eugene Gendlin was working on developing his theory of experiencing. He reformulated Rogers' approach in experiential terms by pointing out the essence of clientcentered therapy (Gendlin, 1974). According to Gendlin, accurate listening is the essence of effective therapy that aims at helping the client to stay in touch with what is going on inside the client. Meanwhile, findings from client-centered Process Scale research suggested that clients who were high in experiencing level, that is, awareness of inner experience, particularly bodily felt feelings, tended to have a successful outcome in therapy (Walker, Ralen, \& Rogers, 1960). Consequently, Gendlin developed a procedure he called Experiential Focusing to facilitate high experiencing level. Client-Centered Therapy and the Emergence of Experiential Psychotherapy

According to Hart (1970), a 30-year span of development of client-centered therapy could be divided into three different periods: the period of non-directive therapy, 1940-1950; the period of reflective therapy, 19501957; and the period of experiential therapy, 1957-1970. Hart referred to experiential psychotherapy as an outgrowth of the non-directive and reflective periods of client- 
centered therapy. Experiential psychotherapy developed out of the efforts of a group of client-centered therapists whose attempts were to offer psychotherapy to hospitalized psychotics and well-adjusted people. Their emphasis shifted from specific therapeutic techniques to a wide range of therapist attitudes and behaviors that were hypothesized to facilitate change.

Rogers (1957) postulated six necessary and sufficient conditions for constructive personality change. These basic conditions include 1) there is a relationship between the therapist and the client; 2) the client is vulnerable or anxious, in a state of incongruence; 3) the therapist is congruent or integrated in the relationship; 4) the therapist experiences unconditional positive regard for the client; 5) the therapist experiences and attempts to communicate an empathic understanding of the client's internal frame of reference; 6) the client perceives the therapist's experience and communication of empathic understanding and unconditional positive regard for the client.

The concept of experiencing as applied to psychotherapy stemmed from Gendin and zimring's work (Hart, 1970). Gendlin emphasized the need for a process 
view of the nature of human experience, which is different from that of a traditional static content approach to personality. As a result of the accumulated works of Rogers, Gendlin, Zimring, Jenney, and Shlien, Rogers redefined self as a reflexive awareness of the process of experiencing (Gendlin, Beebe, Cassens, Klein, \& Oberlander, 1968). The assumption was that if Rogers' necessary and sufficient conditions are present, the client will experience a flow of process of change that involves moving from a rigid mode of experiencing, which is bound by the structure of past experience, to experiencing which is immediate and interprets meaning based on present experience (Rogers, 1958).

Rogers' process view of change regards psychological functioning as a continum of process that also applies to an individual's experience of self. At one end of the continuum, the individual's experience of self is limited by the cognitive maps of the past and is inconsistent with experience, and at the other end the individual's experience of self is synonymous with experience. A well adjusted individual is fully aware and present, able to accept and cope with one's constantly changing experience effectively in accordance with "a harmonious balance of 
organismic direction" (Rogers, 1958, p.149).

Gendlin (1974) considered listening to be a "baseline requirement making all other forms of interaction safer and more effective" (p.226). He claimed that the essence of client-centered therapy was not fully understood and learned by the mental health profession. According to Gendlin, the essence of client-centered therapy is not merely saying back what was said by the person being listened to. It is the kind of listening that enables the person being listened to to stay constantly in touch with the directly felt concrete experiential datum. He referred to this kind of listening as listening with exact. specificity. As a result, this new specification was added to client-centered therapy by Gendlin that later became the basis of Experiential Psychotherapy. In an experiential approach, the person being listened to is asked to check inwardly each response said back by the listener. With this inner checking, a response can be made exact to facilitate a direct contact with what is in the person. Therapy is made more experiential this way.

The basic principle of an experiential approach is that the experiencer directly senses into what is concretely felt. The accuracy of a listener's response can 
be checked with the directly felt experience of the experiencer. A physical release or a further step in the experience may also arise in what is concretely felt (Gendlin, 1974). Change occurs when the process of experiencing becomes fuller and moves beyond where there was blockage. This inner checking with the directly felt experience allows the experiential approach to be used with all concepts, techniques, and theories. It allows a therapist to keep one's existing theoretical orientation and to use it experientially.

An instrument developed from Rogers' client-centered and Gendlin's experiential approaches, the Experiencing Scale, measures the quality of a client's involvement in psychotherapy (Klein, Mathieu-Coughlan, \& Kiesler, 1986). The scale was designed to measure seven levels of client experiencing when applied to tape recordings or transcripts of therapy sessions. The seven levels define the progression of client involvement in therapy from impersonal, detached, and intellectual at the lower end, to descriptive of feelings and explorative at midpoint, and in touch with felt experience and a new step of resolution at the higher end. 
Content and Process of Expexiential Focusing

Focusing was developed by Gendlin (1981) as a practical tool to facilitate or enhance experiencing. It was first referred to as Focusing by Gendlin and later referred to by others as Experiential Focusing. The words Experiential Focusing and Focusing will be used interchangeably to adapt to the context in the following text.

According to Gendlin, Focusing is a process through which an individual attends quietly to the bodily felt sense of a concern and waits for the meaning to emerge from it. However, Focusing is not restricted to any set of steps or procedure. Gendlin (1996) argued the importance of not mystifying Focusing. He defined "Focusing" simply as "spending time with the at first unclear body sense of a problem, so that new steps come" (p.303-304). He also referred to Focusing as a little door. What the individual finds through the door depends on the individual. He emphasized the need to keep the definition of Focusing simple so that people can learn it.

According to Gendlin (1981), Focusing is not just feeling without thinking. It is the kind of thinking that is in touch with what the unsplit body-mind already knows 
and lives. This is what makes Focusing more powerful than thinking or feeling alone. Gendlin argued that Focusing is analogous to a scientific approach. When one's felt sense is used as the touchstone, one can test out different concepts, assumptions, or theories against one's concretely felt experience to understand, create, and live further the meaning of one's existence.

Felt sense and Focusing attitude. Focusing involves two essential elements: felt sense and Focusing attitude. Gendlin (1974) considered a felt sense as "both psychic and bodily" (p. 241). According to Gendlin (1974, 1981), a felt sense is an implicitly complex and not yet conceptually clear bodily-felt whole of a person, situation, or event, which encompasses everything one feels and knows about the given subject at a given time. In the concretely felt bodily sense of a concern, there is an as yet unclear felt meaning and direction. Implicit in that bodily knowing is the next growth step for the organism. If one allows a felt sense to open up and move forward on its own, one will experience a shift. This shift is the source of basic change and is experienced as a distinct physical shift in the bodily sense of the concern. The problem may not be solved, but the way it is carried or experienced in the 
body is different (Campbell \& McMahon, 1985; Gendlin, 1986).

According to Gendlin (1974), a special condition is needed for the Focusing process to unfold. This special condition is referred to as the Focusing attitude: a quiet, gentle, curious, non-judgmental, accepting, letting, allowing, and friendly attitude toward what is coming from inside oneself. It is a different way of being with one's problem. In fact, from a Focusing perspective, the problem is not a specific issue. Rather, the problem is originated by an attitude that interrupts or blocks one's naturally forward moving organismic process. The adoption of a Focusing attitude is, in and of itself, a step toward overcoming of the very attitude that originated the problem (Campbel1 \& McMahon, 1985; Gendlin, 1981, 1986).

In other words, a psycho-physiologically tensed posture often triggers a physiological fight-or-flight response or a psychological defense mechanism that leads to distortion of perception or blockage of the natural rhythm of need fulfillment and tension release. In contrast, the Focusing attitude tends to facilitate a relaxed and alert state in which the organism's natural rhythm of need fulfillment and tension release is available to the 
Focuser. The individual is more likely to experience all aspects of a problem, and a whole spectrum of options become available for problem solving.

Healing force implicit in the felt sense. Gendlin (1996) asserted an underlying assumption of Focusing: the organism's capacity to "fill in the gaps, the needed and implied events that never happened" (p. 280). Gendlin observed that the felt sense carries the answer to what is needed for an individual to restore a sense of well being. Furthermore, implicit in the felt sense is that sense of well being one has yet to experience and longs to experience.

Others called it the inner knowing, the implied direction or solution, the healing energy, the forward moving life energy, or the forward moving organismic process implicit in each felt sense of an issue (Campbell \& McMahon, 1985; Cornell, 1996). The underlying assumption is that "each problem implies its own solution, and Focusing helps explicate this" (Klein, 1995, p. 7).

The procedure of Experiential Focusing. Focusing can be simply defined as a process through which one becomes in touch with one's immediate experience as felt in the body as well as the meaning carried in it. In this focusing 
process, one works through an "implicitly complex, directly felt blockage and its release through experiential carrying forward" (Gendlin, Beebe, Cassens, Klein, \& Oberlander, 1968, p. 230). Gendlin emphasized that Focusing is not a specific set of steps or procedures. It can be done in many ways. However, Gendlin (1969) outlined three preliminaries in the Focusing process. First of all, one shifts one's awareness to attend to one's experience from inside out, stays quiet, and listens to the bodily felt version of an issue. Second, one senses the issue as a whole and lets the meaning come from how the whole issue feels in the body. Third, one waits for words that carry an experiential effect to come from the felt sense. A felt shift, which often is characterized by a sense of relief, occurs with the emergence of these words.

Gendlin (1981) described a "six movement" process as a general guideline for doing Focusing. To prepare oneself for Focusing, one sits quietly for awhile with a sense of general physical comfort. The first movement of focusing is clearing a space. The Focuser mentally lists problems that keep one from feeling "all okay" in life. The purpose is to acknowledge issues of concern in life and to stack them aside without getting caught up in them. As a result, the 
Focuser can create some space amidst life concerns in order to work on a specific problem.

The second movement of Focusing is feeling the felt sense of the problem. After setting aside all the concerns, the Focuser identifies one problem that feels the worst and focuses on it. The Focuser stays silent, Iistens, and feels the whole of the problem. It is crucial to allow the felt sense to come in its own way, which includes the timing, the form, and the intensity it takes. The felt sense is felt as "the holistic, unclear sense of the whole thing" (Gendlin, 1981, p.55).

The third movement of Focusing is finding a handle. Once the problem is felt as a whole in a bodily way, the Focuser begins to find words to describe the feel quality of the felt sense. The aim is to look for something that best describes the core of the felt sense. It may be a word, a combination of words, or something like a picture, an image, or a gesture. However, the problem may already begin to change in the process. The Focuser needs to let go of any preconceived ideas of the problem and look for a word or image that comes with a body shift. The word or the image one uses to describe the quality of the feit sense is called "a handle." A slight stirring or easing of the felt 
sense occurs when a handle is right.

The fourth movement of Focusing is resonating the handle and the felt sense. The Focuser takes the word or image from the third movement and checks it against the felt sense. In order to Eind a match, the Focuser needs to allow the felt sense to come back as it is felt at this moment. Sometimes the handle word or image needs to be modified to fit the felt sense as it is now. Both the handle and the felt sense need to be allowed to move or change in order to resonate with each other and to have an exact match. A sense of rightness comes with finding a perfect match. Then the Focuser needs to stay with this sense of rightness for a moment for the body to do whatever it needs to do--to continue to release, to process, to move, or to change.

A shift or a bodily release may occur anywhere in the foregoing process. The shift is experienced as a distinct physical change in the bodily felt sense of the given problem. The Focuser experiences a sense of easing or release of tension, a sense of fresh air or energy flowing. The shift is accompanied by or in response to the answers that emerge from the felt sense. If a shift occurs prior to the fifth movement, the Focuser may skip to the sixth 
movement to receive whatever happened. However, oftentimes finding a handle and resonating the handle and the felt sense result in only a small shift that in and of itself is not enough to change how the problem is carried in the body. Then one may move on to the fifth movement.

The fifth movement of Focusing is asking. The Focuser asks the felt sense open-ended questions to help facilitate a shift in felt sense. Examples of questions that may facilitate a felt shift are "what is the worst of this?" and "What does the felt sense need?". The Focuser needs to wait for the answer to come directly from the felt sense and refrain from answering the question mentally. In this way, a shift may occur with an answer that comes from the felt sense. One always feels better when a shift does occur. The problem may still be unresolved. However, the way the problem is carried or felt in the body is different. One does not control when or how a shift occurs or if it occurs at all. One has already done Focusing when one spent time sensing and listening to the unclear felt sense of a problem. One can always approach the problem freshly next time if no significant shift is experienced the first time.

The sixth movement of Focusing is receiving. Not only 
does the Focuser welcome and receive whatever comes in Focusing but also makes an effort to protect what does come. One need not "believe, agree with, or do what the felt sense" said, but rather simply receive it (Gendlin, 1981, p.60). Whatever needs to be heard and received first may lead to something quite different later. What one finds in Focusing is only a step of a continuing process. One can learn to stay a little distant from it the way one creates space between oneself and the problem. One maintains space between oneself and whatever comes with the felt sense. There is space between oneself and the problem and space between oneself and whatever comes with the felt sense. There is room to breathe. One has a problem but one is not the problem. Focusing is a process in which one's body is experienced as a process of change. From the perspective of Experiential Psychotherapy, this is by definition the essence of mental health. Research Related to Experiential Focusing

A number of studies have explored Focusing in relation to creative writing, business, problem-solving, spirituality, and dreams (Gendlin, 1981). In the following, an attempt is made to summarize findings in Experiential Focusing related research. 
Experiencing research. Focusing related research began as a series of studies that examined the relationship between experiencing level and the outcome of psychotherapy (Gendlin et al., 1968). In those studies, the Process scale was applied to tape recordings of sessions of neurotic clients. The process scale is a reliable measure of client experiencing level that measures brief excerpts from taperecorded therapy sessions with a classification system of in-therapy behavior. The Process scale consists of four subscales: the experiencing scale, the scale for rating of personal constructs, the scale for rating the manner of expression, and the scale for rating the manner of relating. The findings indicated that "the more successful clients showed significantly higher levels on the Process Scale both early and late in psychotherapy" (p. 224). The same findings were reconfirmed in a study with hospitalized schizophrenic patients (Rogers, 1967). The successful patients were higher on the Process Scale measures than the non-successful patients.

A research effort was made to combine and reanalyze data of 38 neurotic cases and 12 schizophrenic cases from previous studies to examine questions unanswered from those studies (Gendin et al., 1968). In this study, levels of 
experiencing were rated by the Experiencing Scale (EXP), one of the four scales of the Process scale. The findings suggested that both neurotic and schizophrenic cases showed a strong relationship between initial EXP level and outcome. High EXP level was either present from the beginning for the successful patients, or a good outcome was a result of the patients' developing experiencing ability in therapy. The study seemed to suggest that "Focusing ability does not define adjustment, but is necessary to move from maladjustment to adjustment" (p. 229).

Personality traits of Focusers. Gray (1976/1977) and VandenBos (1973/1974) summarized findings from four studies with regard to introverted and extroverted personality type differentiation between people untrained in Focusing but who did (Focusers) and did not (non-Focusers) show an ability to Focus. These studies found no significant difference between Focusers and non-Focusers on the cattell Introvert/Extrovert Scale, Rotter Internal-External Locus of Control Scale, Eysenck Introversion-Extroversion Scale, or the Myers-Briggs Type Indicator ExtroversionIntroversion Scale.

As cited in VandenBos (1973/1974), VandenBos and 
Miller examined the relationship between Focusing ability and the personality types based on the Myers-Briggs Type Indicator scale (MBTI). In this study, 33 volunteer college students were recruited and divided into two groups of Focusers and non-Focuser based on their untrained Focusing ability. VandenBos and Miller found a significant difference between Focusers and non-Focusers on one dimension of the MBTI. High Focusing ability was related to intuition (utilization of the unconscious process), whereas low Focusing ability was related to sensing (utilization of direct physiological sensory perception). The results also suggested that focusers were more flexible and utilized more sources of information.

The association of high Focusing ability with access to more sources of information was also found in Miller's study (Gray, 1976/1977; Oberhoff, 1990/1991; VandenBos, 1973/1974). Miller administered the Rorschach to 50 hospitalized schizophrenics to examine the relationship between untrained Focusing ability and the use of preconscious processes. The protocols were scored by two raters for the participant's ability to regress in the service of the ego. Adaptive regression refers to the participant's ability to make constructive use of the 
preconscious material, whereas maladaptive regression refers to the inability to do so. The study showed that Non-Focusers were evenly distributed between adaptive and maladaptive regressors, whereas most of the Focuser were adaptive regressors. This seemed to indicate that Focusers tend to have more access to and make constructive use of preconscious material.

Another study offered support for the Focuser's cognitive ability to narrow attention on relevant information. Zimring and Balcombe (1974) examined the relationship between the ability to handle emotional information and the cognitive ability to narrow attention to relevant information. Two measures of the ability to handle emotional material were correlated with two cognitive tasks. The Post Focusing Questionnaire and Thematic Apperception Test were used to test 21 participants' ability to handle emotional material, whereas the tachistoscopic test and the sentence memory test were used to test cognitive ability. The results showed that participants who were high in untrained focusing ability were more capable of handling cognitive tasks that involved the participants' ability to selectively focus on relevant and ignore distracting stimuli. Zimring and Balcombe 
interpreted this cognitive ability of Focusers as the ability to differentiate emotional information and to go deeper into the issue.

Wolf reanalyzed the data of two earliex studies by Richert and Drury to examine perceptual differences between untrained Focusers and non-Focusers (Gray, 1976/1977; VandenBos, 1973/1974). In Richert's study, Focusing ability was compared with the ability to estimate time on the Time Sense Test. Drury examined the relationship between Focusing ability and field dependence by way of witkin's Rod and Frame test. The conclusion from reanalyzing the two results suggested that Focusers are moderately field independent, tend to be less rigid, and are open to more sources of information than non-Focusers. In addition, Focusers seem to be able to evaluate a given situation and to alter their behavior to fit the situation.

Several studies also suggested other differences among untrained Focusers and non-Focusers. Gendlin et al. (1968) examined the correlation between Focusing ability and the Cattell High School Personality Inventory's personality descriptions of 47 high school students. The findings showed that participants who were high in Focusing ability tended to be more intelligent, more self-disciplined, calm, 
relaxed, less anxious and more emotionally stable, more sensitive, and had more access to their own affective material. This finding is consistent with the result of two other studies by Drury and Platt. In Drury's study Focusers were found to make significantly more references to emotions and give more detailed descriptions of enotion in TAT stories. Meanwhile, Platt's findings showed that Focusers tended to rate themselves as sensitive on a selfreport adjective checklist (Gray, 1976/1977; VandenBos, $1973 / 1974)$

Gendlin et al. (1968) examined the relationship between untrained Focusing ability and creativity. Twentytwo college students were given three tests in a group situation. The three tests were the Hidden Figures Test, Thematic Apperception Test, and the Focusing Manual. The results showed that Focusing ability was associated with the ability to do well on the Hidden Figures Test. In the Hidden Figures Test, creativity is defined as the ability to let go of constructs and to flexibly adapt patterns. This finding seemed to indicate a correlation between Focusing ability and this type of creativity. No relationship was found between Focusing ability and the ability to generate stories on the TAT. The researchers 
argued that the ability to invent stories unrelated to felt experiencing might not relate to the ability to Focus.

Focusing training and measurement of Focusing ability. VandenBos (1973/1974) studied whether Experiential Focusing can be taught in a brief period of time. Sixty-four volunteer participants identified as non-Focusers, who were untrained in Focusing and didn't demonstrate Focusing ability, were recruited from a university student population. Participants were divided into three training groups and one no training control group. Participants of the three training groups were taught Focusing via one of three training methods: standard Focusing manual presentation, affective association training, and partial desensitization. The Focusing training was conducted in two sessions. In addition, response to Focusing training was examined with regard to three personality attributes: associative ability, openness to affect, and degree of psychopathology. The results showed a significant increase in Focusing ability for all three training groups regardless of the context of the Focusing training or the personality attributes. This finding seemed to support GendIin's (1969) contention that Focusing can be learned by anyone. 
Two instruments have been developed to measure Focusing ability: the Post Focusing Questionnaire ( $P F Q$ ) and the Post Focusing Checklist (PFC). The $\mathrm{PFO}$ is an open-ended questionnaire that uses judges to assess the description of a subject's Focusing experience. The $\mathrm{PFQ}$ was initially presented by Gendiin et al. (1968) and went through several revision processes to reach its current form. Several studies obtained inter-judge correlation of .80 or better using the $\mathrm{PFQ}$ and its scoring procedure (VendenBos, 1973/1974). A score of 3 or more is defined as successful Focusing. The $\mathrm{PFQ}$ is currently regarded as a reliable measure of Focusing ability (Gendlin, 1969; Gendlin et al., 1968; VandenBos, 1973/1974).

The PFC is an objective measure of Focusing ability that does not require inter-judge reliability. It consists of 28 items that assess whether or not Focusing has occurred (Gray, 1976). Items that do not reflect Focusing are tabulated to form a score. Low scores reflect the presence of successful Focusing. Research studies that examined the correlation between the $\mathrm{PFC}$ and the $\mathrm{PFQ}$ indicated cut-off points on the PFC. A score of six or less reflects successful Focusing, whereas a score of 18 or more indicates unsuccessful Focusing. Scores of seven to 17 
suggest the occurrence of some of the phases of the Focusing process. Studies showed that correlation between the $\mathrm{PFC}$ and $\mathrm{PFQ}$ ranged from -.74 to -.89 . The $\mathrm{PFQ}$ and $\mathrm{PFC}$ have been used in clinical studies and studies related to the personality traits of Focusers (Loynes, 1984/1985; Oberhoff, 1990/1991; VandenBos, 1973/1974). The effects of Experiential Focusing. Kantor and Zimring (1976) examined the effect of one Focusing session on the participant's experience or perception of a problem by comparing a story written about the problem with or without having Focused on the problem. Forty-seven participants untrained in Focusing were randomly assigned to an experimental or control group. Among those participants, 23 were identified as Focusers and 24 as nonFocusers based on their PFQ (Post Focusing Questionnaire) scores. Participants were first instructed to identify and describe in writing a general problem with two specific situations involving the problem. Participants were asked later to use the two situations to write two stories. In between the writing of the two stories, the experimental group participants were asked to Focus on the general problem whereas the control group participants completed an irrelevant task to insure that they weren't Focusing. 
The 43 pair of stories were given to judges to rate the number of emotional referents and the experiential quality of each story. The results showed that Focusers became aware of and reported more feelings in the second story after their Focusing session. However, this result is different from the researchers' expectation that Focusing may lead to a redefinition of the problem by way of uncovering hidden core feelings behind the problem. The researchers argued that more than one Focusing session might be required to enrich one's experience of a problem that may then lead to a redefinition in the experiential quality of a problem.

Greenberg and Higgins (1980) examined the effect of two methods of conflict resolution. The two methods employed were Gestalt two-chair dialogue and Focusing. Forty-two graduate students untrained in Focusing volunteered for the study. Participants were randomiy assigned to three conditions: Gestalt, Focusing, and notreatment control group. All participants were instructed to identify an intrapersonal conflict. Participants in both treatment groups received one session of their respective intervention, Gestalt two-chair intervention or Focusing intervention. The Experiencing Scale was used to measure 
the depth of experiencing of the participants. The Target Complaint Box Scale was used to measure the degree of discomfort before and after treatment. An awareness questionnaire was used to measure the participants' changes in awareness before and after treatment.

The findings showed significantly greater shift in awareness and progress over the week for both treatment groups. The Focusing treatment group resulted in as much change in awareness and progress as the two-chair treatment group. However, Focusing led to a higher level of experiencing and shift in awareness, whereas the two-chair method appeared to produce a more direct experience of, and confrontation of, the conflict.

Gray $(1976 / 1977)$ used a clinical population to examine the effect of Focusing on state anxiety and problem-solving ability. Sixty volunteer participants from a three day treatment program, who were not trained in Focusing before, were randomly assigned to three treatment conditions: hypnotic relaxation with problem-solving suggestions, standard Focusing training, and hypnotic relaxation with Focusing training. The treatment consisted of three sessions in one of the three conditions. The pre-test and post-test measures for the study were the State-Trait 
Anxiety Inventory and the Means-Ends Problem-Solving procedure. Participants who received Focusing training were administered the $\mathrm{PFQ}$ and the PFC to assess Focusing ability.

Results showed that all three treatment conditions helped reduce state anxiety and increase problem-solving ability. However, the treatment condition consisting of hypnotic relaxation with Focusing training seemed to be more effective in teaching the Focusing procedure than the standard Focusing training for this clinical population. The findings seemed to suggest a positive treatment outcome for a severely disturbed clinical population.

Focusing and its physiological correlates. Don $(1977 / 78)$ used Focusing to examine the electroencephalograph (EEG) correlates of changes of conscious experience. Five adult participants who claimed to have success with Focusing were selected through preliminary screening sessions. The left occipital EEG was recorded and analyzed by a digital computer. Participants' verbal reports of internal experiences were recorded so that corresponding EEG polygraph tracings could be easily identified. Participants reviewed their own tapes and selected 1) moments of unusual insight and psychological 
movement (felt shift) and 2) moments of least amount of psychological movement.

The research hypothesis tested was that significant changes in conscious experience involve brief stabilization of the occipital EEG at its dominant alpha frequency and respective subharmonics. The results showed that alpha and theta brain wave patterns changed just before the felt shift of the Focuser. This finding seemed to confirm a physiological correlate to the subjective experience of the Focuser.

In summary, a review of the literature on Experiential Focusing seems to indicate that 1) Focusing facilitates change through facilitating a high experiencing level in an individual; 2) Focusing can be learned and used as a selftherapy technique by non-professionals or as a therapeutic technique by professionals; and 3) Focusing can be applied to many areas of interest. Dream Interpretation is another area to which Experiential Focusing can be applied (Gendlin, 1986). As preparation for discussion of the Focusing approach to dream interpretation, basic information about dreams and other approaches to dream interpretation will first be described. 


\section{Dreams and Dream Interpretation}

Researchers have been working on uncovering the mystery of dreams. Numerous controversial findings and theories have arisen on this subject. In the following section, an attempt will be made to review the literature on types of dreams and on dream interpretation. Types of Dreans

Aserinsky and Kleitman (1953) discovered periods of rapid eye movement (REM) during sleep. They found that clusters of these REMs occur at intervals throughout a normal night's sleep. According to their findings, REMs are associated with a pattern of electrical activity in the brain and with dreaming. As a result, scientists have found a way to measure dreams' physiological correlates and to collect data in the sleep laboratory by awakening the dreamer during REM sleep to solicit a dream report. Since the 1950 's, dependable information has been collected with regard to the physiology of sleeping and dreaming.

However, the correction of old misconceptions and the development of new empirically based information did not bring about a consensus concerning the functions of dreams. Some theories suggest that dreams are an expression of unconscious wishes, others suggest the function is 
physiological, and still others view the function of dreaming as processing of information or emotions. The views range from regarding dreams as the waste to be disposed of by the mind (Crick \& Mitchison, 1986) to dreams as vehicles for mystical experiences (Garfield, 1989; Sanford, 1984).

Many theorists argue that humans are constantly dreaming and become aware of it only when the conditions of consciousness permit (Foulkes, 1985). Research findings indicate that dreaming is not necessarily limited to REM sleep nor is it tied exclusively to sleep (Foulkes, 1985; Foulkes \& Fleischer, 1975; Foulkes \& Vogel, 1965). According to these studies, participants in sleep laboratory would sometimes report small drearns while still awake and fully relaxed. Foulkes (1985) described these small intrusions of dreaming into relaxed wakefulness as "waking areams." He contended that the sleeping mind is not functionally different from the waking mind. Therefore, dreaming need not depend on mental processes that are unique to sleep.

The literature in sleeping and dreaming generally acknowledges three types of dreams associated with sleep. They are sleep onset dreams, REM dreams, and non-REM (NREM) 
dreams.

Sleep onset dreams. The process of falling asleep, which typically involves the first ten minutes of sleep, can be described in two ways: one in terms of EEG sleep stages and the other in terms of psychological progression. The EEG sequence is relatively invariable, whereas the psychological sequence varies from one person to another (Foulkes, Spear, \& Symonds, 1966). Kuhlo and Lehmann discovered a slowing-down of brain wave activity associated with sleep onset (Strauch \& Meier, 1996). A notable characteristic of the sleep onset experiences was their sudden appearance. The dreamer often felt unable to guide the experience. These experiences were primarily vivid visual or auditory impressions that were fragmented, disorganized, emotionally neutral, and elusive.

Ladd and Maury studied their experiences during the onset of sleep and referred to these vivid sensory experiences as 'hypnagogic (leading-to-sleep) hallucinations' (Strauch \& Meier, 1996). Others called these same phenomena 'hypnagogic dreams' or 'hypnagogic images' (Shafton, 1995). Strauch and Meier (1996) argued that these hypnagogic dreams might be labeled as 'little dreams' because of their brevity. When compared to REM 
sleep dreams, these hypnagogic dreams lacked naxrative structure, differentiated composition, and the dreamer's active involvement. However, the sleep onset dream was regarded as dream experience due to its quality of expression. Waking thoughts were more likely to blend into this type of dream because of its nearness to the waking state. In addition, paranormal, apparitional, and out-ofbody experiences occurred most commonly at sleep onset. REM dreams. In a typical eight-hour night's sleep, REM first appears for about ten minutes at 90 minutes after sleep onset and recurs for increasingly longer intervals every 90 minutes, ending in a 45 -minute segment just prior to awakening. A typical adult spends about $25 \%$ of each night in REM sleep. Foulkes (1985) proposed only one dreammaking system. The REM dream is the result when the system operates at its fullest pitch.

Most of the early laboratory dream research was about REM dreams. Many dream researchers used to maintain that dreams were associated with REM sleep only. Participants awakened during REM sleep recalled dreams 80-95\% of the time (Shafton, 1995). More current studies showed that dream recall is possible from all sleep phases. However, dream recollection is most likely to occur when awakened 
from REM sleep. According to strauch and Meier (1996), a dream is remembered when the transition from sleep to the waking state has taken place. The transition is easiest when the dream state is closest to the waking state. REM dreams, like sleep onset dreams and other dreams from a near waking phase, are easier to recall because they are closer to the waking state.

REM dreams are typically storylike (Cartwright, 1977). In addition, REM dreams are intense, vivid, emotional, detailed, eventful, complex, relatively long, and sequential in structure (Moffitt, Kramer, \& Hoffmann, 1993). The content of REM dreams is characterized by selfreflectiveness. Research findings indicated that attending to the meaning of REM dreams was significantly associated with increased self-awareness and decreased psychopathology (Moffitt, Kramer, \& Hoffmann, 1993; Shafton, 1995).

NREM dreams. During a typical eight-hour night's sleep, sleepers awakened any time between REM phases reported either no mental content or NREM dreams. Findings of NREM dream recall varied widely over the years. Drearn recall of the NREM sleep was as little as of initially (Shafton, 1995). Hobson (1989) estimated a 408 rate of successful NREM dream recall that resembled some form of 
ordinary thinking. NREM dreams tend to be more thoughtlike. However, both REM and NREM dreams tend to become more storylike as the night progresses. It seems as if the longer the dream the more coherent and filled with experience the dream will be (Cartwright, 1977). According to Faraday (1972), typical NREM dreams "are...shorter, less vivid, less visual, less dramatic, less elaborated, less emotional, less active; more plausible, more concerned with current problems, more purely conversational, more thoughtlike" (p. 41). Stauch and Meier (1996) presented a similar observation. In their study, "NREM dreams were characterized by reduced abundance of dream elements,... fragmented structure...predominantly static impressions [and] reality-oriented themes" (p.136). Research findings indicated that attending to the meaning of NREM dreams was not significantly associated with increased self-awareness and decreased psychopathology (Moffitt, Kramer, \& Hoffmann, 1993; Shafton, 1995).

In summary, findings in dream research seem to indicate that the mind is never entirely at rest even during sleep. Some form of mental activity goes on throughout the night. This mental activity includes sleep onset dreams, REM dreams, and NREM dreams. Although dreams 
of the sleep onset stage, REM sleep stage, and NREM sleep stage vary noticeably in their quantity and quality, these categories also overlap somewhat, making absolutely clearcut classification unrealistic.

Theories of Dreaming

In the past century, scientists and psychologists have battled over antagonistic viewpoints about dreams. Their views range from those who believe dreams to be meaningless waste products of brain metabolism at one end of the continuum to those who view dreams as meaningful. psychological communication at the other end. The following section summarizes various positions of dream theorists who incorporated dream research findings with cognitive psychology, neurophysiology, information theory, or depth psychology

Hobson (1988) is one of those who assumed a mechanistic viewpoint of dreams. He proposed that the brain stem is the dream-state generator and explained the mechanism of dreaming in terms of the periodic spontaneous arousal of the brain stem during sleep. He viewed the raw material in dreams as random sensory signals, muscle impulses, and emotional discharges. From his perspective, dreams are the result of the cerebral cortex's attempt to 
make sense out of the senseless, random accompaniments of autonomous electrical activity in the sleeping central nervous system.

Evans (1983) adopted a computer analogy to describe the phenomenon of dreaming. According to Evans, dreams are impersonal artifacts with no intrinsic meaning. During REM sleep, information is processed for long-term memory with only minimum sensory input from the conscious mind. A dream is nothing but a momentary interception by the conscious mind of material being sorted, scanned, and sifted. He compared dreaming to the brain-computer's off-line time when it processes information gathered during the day and updates its program for the following day.

Crick and Mitchison (1983) proposed their reverse learning (unlearning) theory of dreaming. They described dreaming as the mind's disposal of redundant or erroneous information or dispensable learning of the waking hours. From their perspective, humans dream in order to unlearn or to forget. Interpreting a dream is like studying a rejected document on its way to the incinerator.

Foulkes (1985) claimed that dreams are worth studying as a rich source of information about human minds in general. To Foulkes, dreams are a valuable means to 
understand human automatic mental processing. He encouraged intelligent use of dreams for self knowledge, with the emphasis on the need to be clear about what kind of information dreams might or might not contain. He clarified his perspective as follows:

Even though dream wasn't constructed to make any particular statements, it can still be read for its indications of the mind of the person who dreamed it... [and] can be used to index general properties of the human mind and of human character. (p. 205) In short, Foulkes employed an information-processing model to describe the function of the mind and regarded dreams as only marginally self-revelatory or facilitative for selfunderstanding, which is the goal of dream interpretation.

In later writing, Foulkes (1991) criticized a purely neurophysiological approach to dreams. He maintained that it "is functional/psychological research, and not neural modeling, that advances our understanding of complex mental phenomena... [M] ental phenomena require mentalistic explanations" (p.246). He added that the mental role of the brain stem is poorly understood and that an integrative point-for-point, brain to mind correspondent model is needed. 
Breger (1967) proposed that dreams serve the role of processing emotional information. According to Breger, dreaming works on assimilating new experience into existing affective memory schemata. He suggested that the dream state offers advantages over the waking state for dealing with emotional matexial. The dream state facilitates more fluid association and more ways of manipulating symbols, with minimized social pressure.

Domhoff (1993) adopted the same position and used posttraumatic stress disorder dreams, recurrent dreams, and nightmaxes to support his theory. In replaying the exact event, or sometimes the same theme in a metaphorical form, the emotional information associated with the trauma was processed. By contrast, Cartwright and Lamberg (1992) suggested that the dream function gets stuck and is unable to process and integrate extraordinarily traumatic events.

Hunt (1989) hypothesized that dreams serve a variety of functions. In his theory, dreams serve many different purposes because dreams have multiple functions. Hunt proposed several overlapping categories of dreams. These include mundane dreams, Freudian type dreams, somatic or illness related dreams, metaphorical dreams, problem solving dreams, intuitive or precognitive dreams, lucid 
dreams, nightmares, and Jungian archetypal or mystical dreams. Hunt described his departure from Foulkes's viewpoint by characterizing his approach as a science with heart as opposed to Foulkes's "head science" (1989). Hunt's model provides room for imagery and metaphor as abstract cognitive ability in its own right. According to Hunt, the mind generates meaningful metaphors for the dreamer's life. Hobson (1988), who assumed a mechanistic viewpoint of areams earlier, later came to adopt a holistic attitude about the value of dreams. He acknowledged that dreams serve a similar function to that of a projective test and affirmed the creative and problem-solving capacity of dreams. Hobson conceded that our limited understanding about the human mind says little about how physiology influences mental processes. He allowed that we do not even "really know the origin of the voltages that are measured" (p.135) by the EEG. In short, Hobson (1990) claimed that he is "able to avoid throwing out the psychodynamic baby with the psychoanalytic bathwater" (p.223).

Stevens (1995) reasoned that dreams are psychobiological events. He proposed a comparative method that brings together the findings of psychology, analysis, ethnology, and neuroscience. To him, dream research 
findings from neurophysiology and other fields of studies can be used as complementary information to confirm theories and observations in psychology. Anthropology, psychiatry, neurology, and depth psychology all provide valuable insights into a deeper archetypal reality in humans. This deeper reality is revealed most vividly in dreams, which neuroscientists have attempted to link to the ancient structures in human brains. He maintained that "by granting access to the deepest levels of human experience, dreams can contribute to [human] health and personal development" (p. 5).

Stevens (1995) summarized that the purpose of dreaming is to promote adaptation, growth, and consciousness "by which the life of the individual is grafted on to the life of the species" (p. 139). To dismiss dreams as mere spontaneous axousal of the brain stem or reverse learning is "not only inadequate, it is insulting" (p. 87). He agreed with Liam Hudson's warning to view dream as our 'last wilderness' that is in need of protection. He emphasized that while scientists will continue to elucidate the neurological basis of consciousness, what matters to us is what we do with the consciousness we have.

In summary, neither neuroscientists nor psychologists 
have presented conclusive evidence regarding the functions of dreams. However, observations made from research studies and clinical experience seem to suggest that dreams have both physiological and psychological functions. States (1992) proposed a phenomenological approach to the possible meaningfulness of dreams. He suggested that there is always the possibility that the meaning of dreams lies in the interpretation rather than in the dream itself.

Approaches to Dream Interpretation

The views of the early theorists, Freud and Jung, have had significant influence on current views of dreams and dream interpretation.

Freudian theory. From the Freudian perspective, dreams represent the emergence of repressed infantile wishes or conflicts from the unconscious mind during sleep. Freud (1900/1952) proposed that dreams consist of manifest content and latent content. The latent content, which is the hidden meaning of dreams, is revealed through the process of dream interpretation. Freud (1900/1966) indicated that although the dreamer has the key to the latent meaning of the dream, interpreting one's dreams could be very difficult because of the disguise mechanisms involve in dreams. 
Freud described five types of dream disguise mechanisms: symbolization, representation, condensation, displacement, and secondary revision. Freud proposed two sets of dream symbols. One is unique to the individual's history and the other derives from the collective experience of humanity. "Symbolization" referred to the disguise of latent content by symbols. "Representation" is the mechanism through which underlying feelings or thoughts are transformed into images or concrete situations, whereas "condensation" is the mechanism in which several ideas or experiences are combined into one dream image. Through "displacement" important latent conflict is transferred to something neutral, trivial, or superficial in the dream. The purpose of "secondary revision" is to make the aream appear coherent or logical by editing or connecting elements of the dream.

The primary method used in Freudian dream interpretation is free association (Freud, 1935/1963). The dreamer is asked to freely associate to the dream and its various parts whatever comes to mind. Freud believed that the dreamer would come in contact with the origin of the repressed wishes or conflicts through free associations. In addition, Freud also proposed a list of universal symbols 
that could be used to interpret dream images. The majority of the symbols he proposed wexe sexual in nature.

Jungian theory. Jung viewed dreams as natural, healthy, creative, progressive, and purposive psychic processes. He believed dreams serve to compensate for and expand the limited view of the waking ego (Hall, 1983). Dreams reveal, rather than disguise, other sides of the personality that are crucial to an individual's development. The images in dreams reflect the psychological complexes in the personal unconscious. In other words, dreams serve as a guide to direct the waking ego to focus on and work through particular complexes to achieve balance in life.

Dream interpretation is one of the major treatment methods in Jungian therapy. Association is used as a primary technique to uncover the message of the dream (Hall, 1983). Exploration of associations can occur on three levels: personal, cultural, or archetypal. In addition, interpretation of symbols plays a central role in the Jungian approach (Meier, 1987). Jung rejected the Freudian reductionistic view of the meaning of symbols. He believed that symbols could have meaning that are uniquely individual or that are universally dexived from the 
collective unconscious. The Jungian approach encourages artistic expression of dream images in the forms of art, music, and dance.

Gestalt theory. Gestalt theory represents another major contribution to contemporary theories of dream interpretation. Perls (1969) believed every dream element reflects a projected part of the dreamer's personality. He believed that everything, including the existential difficulty as well as the disowned and the already integrated parts of the personality, is either represented in the dream or can be generated through dream work. The goal of dream work is to help the dreamer integrate splitoff parts of the personality. Working with areams often reveals the dreamer's blocked or unmet needs as well as conflict between polarized parts of the personality (Faraday, 1974).

Gestalt dream work emphasizes the dreamer's experiencing, rather than analyzing, the dream. Gestalt therapists help the dreamer explore the meaning of the dream, rather than interpreting the dream for the dreamer (Fantz, 1983). After recounting the dream in the first person in the present tense, the dreamer is asked to play out different parts of the dream and carry out a dialogue 
with those parts. Through engaging in dialogues with splitoff fragments of the personality, awareness and integration of those fragments become possible.

Contemporary theories. Contemporary theorists have expanded and refined the early theories and techniques of dream interpretation. Hill (1996) and Ullman (1996) are two contemporary theorists whose models have been used in several dream interpretation studies, which are reviewed in a later section entitled Research on Dream Interpretation.

Hill (1996) viewed dreams as triggered by waking events and helping the dreamer encode or assimilate waking experiences into the appropriate schemata. Various cognitive schemata, in which past memories and experiences are encoded, get stimulated by waking experiences. During dreaming, information associated with waking experiences is compared with various cognitive schemata to make the information fit into the appropriate schemata. In other words, Hill viewed dreams as the dreamer's attempt to make sense of the waking experiences through processing the experiences in light of past experiences. The goal of dream interpretation is to use dreams to explore the relevant cognitive schemata to understand the dreamer's reactions to a current conflict and to make appropriate alterations in 
the dreamer's reactions to the conflict.

Hill presented an integrated model of dream interpretation that includes three stages: exploration, insight, and action. In the exploration stage, the dreamer tells the dream, explores and experiences feelings, associates the dream to waking life, and works on conflicts reflected by the dream. In the insight stage, data from the exploration stage is used to facilitate the dreamer's understanding of the meaning of the dream. In addition, the dreamer's schemata is restructured to accommodate new data. In the action stage, data from the exploration and insight stage is used to facilitate changes in the dreamer's life. This may include eliciting motivation for change or exploring and learning alternative skills or behaviors based on the insight. Insight based action is also helpful in consolidating changes in the dreamer's schemata.

Ullman (1996) viewed dreams as a universal phenomenon that has great healing potential. Dreams reveal where an individual is in relation to life by bringing into dreams issues from the physical, psychological, social, and spiritual domain. He believed that dream work should be made accessible to the public outside of the therapy room. Ullman proposed a step-by-step group approach to dream 
interpretation that can be used in both clinical and nonclinical settings. Group members' projections onto the dream as if it were their own help the dreamer gain different perspectives in interpreting the dream. In addition, group members also benefit from exploring aspects of themselves through owning and exploring their projections. A more honest self experienced in the safe presence of others is a healing factor of Ullman's model. The safety of the dreamer in the group environment is highly emphasized in Ullman's model. The dreamer is the one who decides what to share in the group, what aspects of the feedback from other group members fit, and the final interpretation of the meaning of the dream. Skills that are important in maintaining the safety of the dreamer include group members' ability to listen to the dreamer without bias and their ability to engage in dialogues with the dreamer without being intrusive.

Ullman's model consists of four stages. In stage one, the dreamer shares the dream, and group members ask questions to clarify aspects of the dream that did not come across clearly. In stage two, group members work with the dream as if it were their own by offering feelings and meanings they project onto the dream. Stage three includes 
four substages. First, the dream is returned to the dreamer who shares feelings and thoughts associated with the dream. Second, further dialogues develop between the dreamer and group nembers to help the dreamer search for the context of the dream. Questions are put to the dreamer to elicit information and understanding. This is the stage where meaningful exploration relies mostly on the dreamer's experienced level of safety. The third substage consists of playback of the dream to the dreamer. The scene of the dream is read out loud back to the dreamer to facilitate further understanding and felt connections to the dream. Fourth, group members are invited to offer the connections they see between the dream and the dreamer's life. Connections made by group members are viewed as their own projections unless validated by the dreamer. The dreamer is free to respond or not to any of the projected connections offered by the group members. In stage four, the dreamer is invited to take a second look at the dream or to share further insights into the dream in the interval between sessions .

Focusing-oriented dream interpretation. Gendlin (1986) developed a Focusing approach to dream interpretation. He asserted that all approaches to dream interpretation can be 
utilized when anchored in the experiential felt sense of the individual. The touchstone of his model is for the dreamer to check against one's own felt sense the hypothesis for interpretation from different dream interpretation approaches.

Gendlin (1986) noted three advantages to the method he developed. First, the method makes use of all approaches to dream interpretation. Questions adopted from various aream interpretation approaches are made available by Gendlin for the dreamer to use. Each question can be used to check against the felt sense of the dream by the dreamer to interpret the dream. Second, a physical felt shift or tension release is the basic touchstone of the model. There is an unmistakable bodily felt, experiential knowing for the dreamer to differentiate if the interpretation is the right one. Third, the method can be learned.

Gendlin (1986) conceptualized his method of dream interpretation to include two stages. In the first stage, one finds out what the dream reflects but gains no new insight about oneself from the dream. In the second stage, the dreamer discovers new insight or new direction for development. Gendlin included "bias control" in stage two of his method to facilitate new insight or growth 
direction. According to Gendlin (1996), dreamers tend to bring their usual bias to their dreams or dream interpretation. Bias control helps the dreamers go beyond their usual attitude of perceiving and experiencing. New insight or direction may arise when the dreamers try on different attitudes in interpreting their areans. Stage two may occux after stage one, concurrent with stage one, ox not at all.

Gendlin (1986) also identified several aspects of his method that differentiate it from other approaches. First, the interpretation comes from within the dreamer. Every hypothetical interpretation is checked against the felt sense of the dreamer to know if the interpretation is correct. The interpretation is considered hypothetical or reflects the associations projected by others when it leads to no resonance in the dreamer's felt sense. In other words, the major difference between Gendlin's approach and others' lies in the use of the felt sense. Gendlin believed that only the dreamer's body can interpret the dream. Second, the dreamer's privacy is respected. The interpretation can go deeper into sensitive areas only when the dreamer's psychological space is protected. Dreamers will feel safe enough to risk allowing to happen whatever 
needs to happen when they know they don't have to share any aspect of their process that they wish to keep private.

Third, the dreamer guards against interruption by "the critic." The critic is defined as "an inner voice that criticizes and interrupts a person's every hopeful move" (Gendlin, 1996, p. 247). It is interruptive, hostile, and repetitious. The effect of a critic attack can often be recognized as constriction and tightness in the stomach and feelings of guilt or shame. In order for the dream interpretation or Focusing to be effective, one needs to recognize and put aside the critic. Research on Dreams and Psychotherapy

Two studies examined the relationship between dreams and psychotherapy. Cartwright, Tipton, and Wicklund (1980) studied the effect of induced dream recall on client responsiveness to psychotherapy. Participants wexe 48 student clients who applied for counseling service at a university counseling center. They were selected as potential early dropouts from psychotherapy based on assessment of their readiness for counseling and access to feelings and inner life.

Thirty-two participants were offered a two-week program to prepare them for psychotherapy. They were 
assigned alternately to a REM awakening condition or a NREM awakening condition. REM awakening participants were given access to their dreams by awakening them from REM sleep periods, whereas the NREM awakening participants were awakened from NREM sleep periods. All laboratory participants received morning discussion sessions of the recalled dreams. The remaining 16 participants proceeded directly into psychotherapy without preparation. The results showed that participants who went through the pretherapy preparation program and experienced successful aream recall, which includes both REM and NREM dream recall, and dream discussion stayed in therapy at a significantly higher rate and demonstrated more productive in-therapy behaviors than participants who did not go through the preparation program.

In exploring the relationship between dreaming and waking mental Iife, Melstrom and Cartwright (1983) studied the effects of psychotherapy on laboratory-collected dreams before and after psychotherapy. Participants were students who applied for psychotherapy at a university counseling center and met criteria as being low in readiness for counseling. Ten experimental participants were assigned to a REM awakening condition and four to a NREM awakening 
condition to recall dreams. A nontreatment comparison group was used in the study. The comparison group consisted of four participants in dream recall sleep laboratory that did not apply for psychotherapy.

The experimental participants received their laboratory dream recall sessions four nights a week for two consecutive weeks before psychotherapy and two follow-up nights after psychotherapy. Five judges blindly rated participants' dreams for anxiety, guilt, shame, experiencing level, and dreamlike fantasy. The experimental participants and therapists both rated the outcome of treatment on a 9-point scale at the conclusion of therapy. Participants were divided into successful outcome and unsuccessful outcome groups based on the outcome ratings of treatment. The results showed that participants with successful treatment outcome demonstrated increase in dream anxiety level, whereas the unsuccessful participants and the comparison group participants demonstrated little change in dream anxiety.

Melstrom and Cartwright proposed several reasons for the increase in dream anxiety level in the successful participants. One possible reason was that the successful participants had learned to deal with negative feelings in 
a less defensive way and were able to allow themselves to experience and discharge the associated anxiety. The other possible reason was that the high dream anxiety might be a reflection of the stress involved in dealing with the termination of an important relationship with the therapist. Another possible explanation was that the successful participants might be experiencing more anxiety in trying out new behaviors. Whatever the reason might be, they argued that the findings seemed to indicate some relationship between dreaming and waking life.

Research on Dream Interpretation

In contrast to the countless writings and interest in dreams and theories of dreaming and dream interpretation, only a few empirical studies have been conducted on dream interpretation. The following section reviews existing case examples and reseaxch studies that examine the process and outcome of dream interpretation in individual and group settings.

Therapists since the time of Freud have been reporting successful case studies of dream interpretation from their clinical practices. Merrill and Cary (1975) gave case examples of aream analysis in brief psychotherapy that helped college students experience disowned feelings and 
led to relief in symptoms and reduction in acting out. Kolb (1979) also supported Merrill and Cary's claim that dream analysis in brief psychotherapy helped relieve symptoms and reduce acting out. She also provided case examples to validate the hypothesis that dream analysis made brief psychotherapy more productive.

Others also reported successful clinical case examples of the use of dream interpretation in sex therapy and family therapy (Buchho1z, 1990; Bynum, 1980; Levay \& Weissberg, 1979). Levay and Weissberg suggested that dreams are useful in providing understanding and working through of unconscious factors in sexual dysfunction. In integrating aream material into sex therapy, treatment is more likely to be successful and accomplished in a shorter period of time. From a family therapist's point of view, Bynum observed that a family's recurrent transactional patterns are reflected in the family's dream life and presented case examples and methods that illustrated the clinical use of dream material in the context of family therapy. Buchholz also agreed with Bynum's observation that dreams mirror family dynamics and discussed the ways dreams can be used in family therapy.

Several empirical studies examined various effects of 
dream interpretation. Webb and Fagan (1993) utilized psychological kinesiology (muscle testing) as a method to examine the effect of dream interpretation on the frequency of recurring dreams. Twenty-six participants who reported having recurring dreams at least four times a month for a year or more were assigned to either an experimental group or a dream recording control group. Participants in both groups recorded recurring dreams for 30 days as baseline. After the 30-day period participants met with the experimenter individually for one session, continued recording their dreams for another 30 days, and completed an exit questionnaire.

Participants in the control group met with the experimenter to turn in their dream record, describe their dreams, and give associations to understand and interpret their dreans. The experimenter listened without giving interpretation or feedback. Participants in the experimental group met with the experimenter in a single session to interpret their recurring dream using the method of muscle testing. Psychological kinesiology (PK) is a method that uses manual muscle testing to elicit a physical response to verbal questions. In a PK session, participants answer 'yes' or 'no' with their muscle responses to 
questions asked by the examiner. Each question is followed by the examiner's applying pressure to the selected muscle of the participants. Typically, the participant extends an arm perpendicular to the body and attempts to keep it extended while the examiner applies pressure to try to lower the arm. The 'yes' answex is represented by a strong muscle response whereas the 'no' answer is represented by a weak muscle response. A strong muscle response is defined as the ability to resist pressure from the examiner equivalent to 10-15 pounds of pressure and a weak response as an inability to do so. The examiner asks questions that yield specific information and develops an explanation based on the information.

PK dream interpretation began with the participants describing their dreams and giving associations. The experimenter muscle tested questions developed from the participants' areams and associations. An interpretation of the aream was then put together by the experimenter based on the participants' answers to the questions asked. The rationale behind the PK method is that the body can bypass psychological defenses and tends to be more in touch with the person's reaction than one can allow oneself to verbalize. 
The hypothesis of the study was that participants would experience reduction or cessation in the frequency of recurring dreams after the $\mathrm{PK}$ dream interpretation session. The results showed a significant reduction in the frequency of recurring dreams for the treatment group participants but not for the control group participants. As a result, Webb and Fagan suggested that $\mathrm{PK}$ dream interpretation is effective in reducing the frequency of recurring dreams. Additional findings also showed that fewer treatment group participants reported concern about their aream, sleep loss, and awakening from the dream after the intervention. The treatment group participants were also more likely than the control group participants to report changes in their dream and changes in their feelings about the dream after the intervention. They also considered the dream interpretation as helpful and useful, and they learned something about themselves as a result of the dream interpretation.

Cogar and Hill (1992) studied the effect of dream interpretation on enhancing self-esteem and reducing symptomatology. Sixty-seven undergraduate volunteers were randomiy assigned to one of three groups: dream monitoring and interpretation group, dream monitoring group, and 
waiting list control group. In the dream monitoring and interpretation group, participants recorded and participated in six weekly individual session of dream interpretation using the Hill model (Hill, 1996). Participants in the dream monitoring group monitored their dreams for six weeks, whereas participants in the waiting list control group received no intervention or dream monitoring .

The hypothesis of the study was that dream interpretation would increase participants' self-esteem and decrease symptomatology. Furthermore, an additional goal of the study was to examine if two specific personal attributes were related to the effectiveness of dream interpretation. The two attributes examined in the study included psychological-mindedness and the verbalizervisualizer dimension of cognitive style. Psychologicalmindedness was defined as the disposition that consists of cognitive understanding of psychological issues and capacity to experience one's inner life and to share others' feelings. Verbalizers referred to left hemisphere dominant individuals who tend to use words to solve problem, whereas visualizers referred to right hemisphere dominant individuals who use imagery in problem-solving. 
The results showed no significant changes in symptomatology or self-esteem across time or among groups. Cogar and Hill suggested that the absence of pathology and life distress of the volunteer participants before intervention might be responsible for the results. Furthernore, the findings also indicated that psychological mindedness and the verbalizer-visualizer variables did not moderate the effects of dream interpretation. However, all dream interpretation group participants reported increase in understanding of self, feelings, thoughts, behaviors, relationships, unconscious events, and problems.

Another study also examined the effect of dream interpretation on insight, self-esteem, anxiety, and symptomatology (Falk \& Hill, 1995). Falk and Hill's study examined the effect of a dream interpretation group for women in the divorce transition. Thirty-four separated or divorced women were randomly assigned to one of four dream interpretation groups or to a waiting list control group. Dream interpretation group participants met for eight weekly two-hour sessions with one of the group members working on a dream in each session, whereas waiting list control group participants were given a one day workshop on dream interpretation after the post-testing. Participants 
who worked on areams in the group were free to choose whatever contributions made from other group members in terms of associations, interpretations, and actions to understand one's dream. The researchers assumed that the method was also helpful in uncovering the dynamics of associations for other group members who offered projections.

The model used in the dream interpretation group was a combination of the Hill model and Ullman's (1996) group approach to dream interpretation. Falk and Hill hypothesized that dream interpretation groups would help treatment group participants in increasing insight, selfesteem, and coping, and in reducing anxiety and depression. Trained judges used a nine-point Likert scale to rate insight in the participants' recorded dream interpretations. Other outcome measures used in the study were the Rosenberg Self-Esteem Scale, the Beck Anxiety Inventory, the Beck Depression Inventory, and the Impact of Events Scale. Results showed that dream interpretation group participants gained more insight and self-esteem than the waiting list control group participants. However, the level of symptomatology and anxiety did not change significantly as a result of the intervention. Falk and 
Hill argued that the relatively well functioning participants might allow less room for change to occur.

In order to identify the key ingredients that contribute to the effect of dream interpretation, Hill, Diemer, Hess, Hillyer, and Seeman (1993) compared dream interpretation to event interpretation and the interpretation of another person's dream. Sixty undergraduate volunteers were randomly assigned to one of the three intervention conditions. The three conditions were 1) participant interpreted one's own dream, 2) participant interpreted someone else's dream, and 3) participant interpreted a recent troubling event. The second intervention condition in which participants were asked to interpret someone else's dream was included in the study to control for the effects of projection. Hill et al. hypothesized that there would be no difference in the outcome of interpreting one's own dream or someone else's dream if the effect of dream interpretation is attributed to the unveiling of one's projection. The third intervention condition in which participants wexe asked to interpret a recent troubling event was included to control for the effects of interpretation. The researchers hypothesized that a systematic interpretation of a 
troubling event would be as helpful as a systematic intexpretation of one's dream if the effect of dream interpretation is due to the factor of systematic interpretation.

Outcome measures included the Depth Scale from the Session Evaluation Questionnaire, the Mastery-Insight Scale of the Therapeutic Realizations Scale, and the Differential Emotions Scale-IV. The Depth Scale was used to evaluate the depth of the session, the Mastery-Insight Scale was used to assess the level of insight gained by the participants, and the Differential Emotions Scale was used to measure emotion-specific affective-cognitive structures. Results showed that participants who were in the interpreting one's own dream condition rated their sessions as deeper and generated more insight than participants in the other two conditions. Hill et al. suggested that the effect of dream interpretation could not be explained solely by the process of projection or interpretation. They observed that interpretation of one's dream seemed to offer unique insight that is different from the insight gained from interpreting a troubling event or projecting an interpretation onto another person's dream. In an effort to replicate and extend the findings of 
the study by Hill et al. (1993), Diemer, Lobell, Vivino, and Hill (1996) compared the effect of dream interpretation with event intervention within the context of brief therapy. Participants were recruited from people who wanted individual therapy rather than dream interpretation. Among the 25 participants who completed 12 sessions of treatment, 20 were assigned to a treatment group from the beginning and five were initially assigned to a waiting list control group and then to treatment. All participants were scheduled for twelve weekly sessions. Of the eight middle sessions, two were dream interpretation and two were event interpretation. Dream and event interpretation were scheduled in two different sequences to control for the difference in the presenting order of the intervention. Participants were reminded to bring in either a dream or a troubling event at the end of the session preceding an interpretation session. An unstructured session was always conducted between two interpretation sessions.

The results showed that the overall treatment involving dream interpretation, event interpretation, and unstructured sessions resulted in increased personal functioning and event insight and decreased symptomatology. However, there were no significant differences on outcome 
measures of session quality, self-understanding, and insight for dream interpretation, event interpretation, and unstructured middle sessions. According to Diemer et al. the findings seemed to indicate that dream interpretation is as helpful as other therapeutic strategies. These findings did not correspond with those of Hill et al. (1993) .

Diemer et al. suggested that the findings seemed to support Luborsky, Singer, and Luborsky's (1975) observation of the equivalent efficacy of different forms of psychotherapy. Furthermore, Diemer et al. also suggested that the results needed to be interpreted in light of the possible ceiling effect of the outcome measure. In other words, it was difficult for dream interpretation to be better than other interventions that were already better than the average.

One study examined the process of dream interpretation in a group context (Shuttleworth-Jordan \& Saayman, 1989). In the study, the processes of two highly systematized methods of dream interpretation were examined by comparing changes in levels of tension at sequential procedural steps. Twenty-one undergraduate volunteer participants matched for age, gender, and anxiety level (within a range 
of average to high anxiety level) were randomly assigned to one of two treatment groups or a nontreatment control group. All participants were required to keep nightly dream records.

Participants in Group One received the ShuttleworthJoraan, Saayman, and Faber (1988) method, which consisted of four steps: relaxation, presentation of dream, amplification (dreamer and group members work together to elaborate the meaning of the dream via association), and closure. Group Two participants received Ullman's (1996) group approach that included five steps: relaxation, presentation of dream, group members' projection onto the drean, amplification, and closure. The difference between the two methods was in the group projection step included in Ullman's approach. Treatment group participants went through ten 90-minute dream interpretation sessions, with one member working on one dream each session. At the end of each session, participants completed a 10-point thermometer-like fear scale to indicate the amount of tension they experienced at each step of the process.

The hypothesis of the study was that Group one results would reveal moderately high levels of tension as manifested in alert-involved nondefensive activity. 
Meanwhile, the researchers hypothesized that the inclusion of the projection step in Group Two would show very low or excessively high levels of tension as manifested in highly defensive activity. Results showed a significant increase in tension over baseline for Group One participants to levels associated with highly oriented and minimally defensive activity. For Group Two participants, tension levels remained the same across all steps in the process. In posttreatment interviews, Group one participants reported a high level of involvement and no sense of loss of control or strong anxiety. However, Group Two participants reported feeling frustrated and uncomfortable at the group projection step. The researchers interpreted the findings as an indication that the group projection step was counterproductive and promoted defensive reactions.

As illustrated in the foregoing section, empirical findings in dream interpretation research can be briefly summarized as follows. Webb and Fagan (1993) found that psychological kinesiology was more effective in reducing the frequency of recurring dreams than a dream recording control condition. Falk and fill (1995) found that group dream interpretation was more effective than a waiting-list 
control condition in enhancing insight and self-esteem but not in reducing anxiety and symptomatology for women in the divorce transition. Hill et al. (1993) found that interpretation of one's dream promoted greater depth of experience and insight than interpreting a recent event or another person's dream. Cogar and Hill (1992) found that dream interpretation was not effective in reducing anxiety and symptomatology for non-distressed volunteer student participants. Diemer et al. (1996) found that dream interpretation was as effective as event interpretation or unstructured sessions in enhancing personal functioning and insight and in reducing symptomatology. In other words, existing dream interpretation research findings seem to offer some support for the efficacy of dream interpretation. However, Cogar and Hill (1992) suggested that more empirical studies are needed to answer the many untested hypotheses in the theory and clinical practice of dream interpretation. Several of the researchers pointed out the need for developing measures that are sensitive to the effects of dream interpretation (Cogar \& Hill, 1992; Falk \& Hill, 1995; Hill et al., 1993). They referred to dream interpretation specific effects as insight, changes in distressing response to dream, and changes in dream 
content and frequency rather than personal functioning or symptomatology. However, a review of the existing literature found no published or previously researched inventories designed to measure the dream interpretation effects specified by previous researchers. Research on Experiencing Level and Dreams One study examined the level of experiencing in dream reports (Hendrick \& Cartwright, 1978). In this study, twenty participants were awakened during REM sleep to collect dream reports in a sleep laboratory. One hundred and four dreams were rated via the Experiencing Scale (EXP) for level of dream experiencing. High experiencing level of a dream report refers to explicit references to feelings by dream characters, whereas low experiencing level includes descriptions of events that lack personal response or involvement.

Research results showed that dream experiencing level was highly stable for individuals. Body Sophistication scores, as measured by Witkin's Body Sophistication Scale, were found to be significantly related to dream EXP scores at beyond .05 level in the predicted direction. The finding seemed to offer support for the research hypothesis that participants who were high in dream experiencing level 
tended to be more psychologically differentiated. Psychological differentiation is referred to as an individual's separate sense of self in terms of experiences of the world. Furthermore, no significant relationship was found among dream experiencing level, defensiveness, and the personality trait of extroversion-introversion. In other words, the results seemed to indicate that dream experiencing level is independent of defensiveness and the personality trait of extroversion-introversion.

Four participants from the same sample, who were identified as having initially low waking experiencing level, were selected for additional intervention. They participated in a dream workshop designed to manipulate the dream EXP level to increase it. The results showed that dream experiencing level is difficult to raise. However, the content of the participants' dreams suggested that attitude toward the experimenter and toward selfexploration may influence their trust and openness to the training and to a change in aream experiencing level.

\section{Summary}

The litexature on dream interpretation indicates some support for the efficacy of dream interpretation. However, researchers also suggested the need for more empirical 
studies on the topic, with an emphasis on developing measures that are sensitive to the specific effects of dream interpretation.

The literature on Experiential Focusing indicates that Focusing can be applied to many areas of interest. Dream interpretation is one area to which Experiential Focusing has been applied. However, a review of the existing Iiterature found no research conducted on Focusing and dream work.

Taken as a whole, the literature points to a need for more research on Focusing and dream work as well as the development of an instrument that is sensitive to the effects of dream interpretation. This study was designed to fulfill both needs. The researcher first developed a preliminary instrument that is sensitive to the specific effects of Focusing-oriented dream work. The researcher then used the instrument along with a structured interview in a pretest-posttest control group design to examine the effects of dream interpretation using Focusing. 
CHAPTER II

\section{METHODOLOGY}

The purpose of this study was twofold. In the first part of this study the researcher developed a preliminary instrument that is sensitive to the effects of Experiential Focusing-oriented dream interpretation. In the second part, the researcher used the instrument along with a structured interview in a pretest-posttest control group design to examine the effects of Experiential Focusing-oriented dream interpretation.

This study was designed to answer the following inquiries: 1) Can a preliminary instrument with validity and reliability be developed to assess seven effects of Focusing-oriented dream interpretation? 2) What will be the effects of Focusing-oriented dream interpretation?

First Part of the Study: Development of Part one of the Dream Interpretation Effects Questionnaire

\section{Research Hypothesis 1}

1) A preliminary instrument with validity and with reliability at .80 level or higher can be developed to 
assess seven effects of Focusing-oriented dream interpretation.

Development of Instrument Items

The researcher developed Part one of the Dream Interpretation Effects Questionnaire (DIEQ) to assess the major effects of Focusing-oriented dream interpretation. Based on the existing Experiential Focusing and dream interpretation literature, the researcher proposed seven categories of major effects possibly reported by someone who has experienced Focusing-oriented dream interpretation: (1) a sense of easing or release of tension associated with the dream, (2) a sense of fresh air or increase of positive energy associated with the dream, (3) increased selfunderstanding, (4) a sense of movement, reconciliation, or healing, (5) development of a new step or new direction regarding a concern, (6) enhanced valuation of dreams, (7) enhanced understanding of the meaning of the dream.

As pointed out in the synthesis of related literature section, category (1), (2), (4), and (5) reflected specific effects associated with Experiential Focusing but could result from any approach to dream work. Category (3), (6), and (7) reflected effects of dream interpretation based on the findings of existing empirical studies. Each category 
was represented by six to eight items on the DIEQ. No less than one-third of the items for each category were stated in "negative" syntax (Appendix C). After reading each statement, the participant circled one response on a 7point Likert scale from "not at all like me" to very much like me." Appendix $c$ was used to develop the pilot form of Part One of the DIEQ (Appendix D).

\section{Selection of Participants}

The researcher took steps to recruit a minimum of 40 volunteer participants. The researcher approached graduate students in Counselor Education courses at the University of North Texas and explained the study. Those who agreed to participate signed an informed consent form (Appendix A) . All those signed were included in the study.

\section{Procedures}

The researcher instructed the volunteer participants to pair up. One shared the dream while the other listened without making any interpretation. The dreamer began by telling the dream to the listener and then freely associating the meaning of the dream. The dreamer then filled out Part one of the DIEQ. The dreamer and the Iistener switched roles and went through the same process. 


\section{Limitations}

The first part of this study has the following limitations:

1) The number of participants was small and generalizability is limited by the use of participants who were graduate students in Counselor Education courses.

2) The use of volunteer participants presents another limitation. According to Heppner, Kivlighan, and Wampold (1992), volunteer participants tend to be better adjusted, better educated, more intelligent, less authoritarian, and have a higher need for social approval. As a result, the research results may suffer a lack of generalizability.

\section{Collection of Data}

The researcher planned to administer the pilot form of Part one of the DIEQ (Appendix E) to a minimum of 40 participants to establish its reliability. All volunteer participants completed Part one of the DIEQ after reporting a dream and freely associated its meaning to another participant. The information gathered constituted the quantitative data of the first part of the study.

\section{Analysis of Data}

The data from Part one of the DIEQ was keyed into the computer and analyzed using SPSS for MS Windows Release 6.0 
(Norusis, 1994) For the purpose of this study, a Cronbach alpha of .80 or higher was considered reliable, $.65-.79$ marginally reliable, and .64 or lower unreliable.

Second Part of the Study: Effects of FocusingOriented Dream Interpretation Research Hypotheses 2-5

2) Participants in the experimental group will attain a significantly higher mean score on posttest than on pretest as indicated by Part one of the DIEQ.

3) Participants in the control group will attain no significantly higher mean score on first posttest than on pretest as indicated by part one of the DIEQ.

4) The mean difference between posttest and pretest scores for experimental group participants will be greater than the mean difference between first posttest and pretest scores for control group participants as indicated by part One of the DIEQ.

5) Participants in the control group will attain significantly higher Part one DIEQ mean score on second posttest after the intervention than on first posttest after the 45-minute waiting period.

\section{Research Question}

Are there observable patterns in the qualitative data 
gathered in this study through the Cover Page, Part Two, and Part Three of the DIEQ and the structured interview?

\section{Definition of Terms}

Focusing is defined as a process by which an individual spends time attending quietly to the initially unclear body sense of a concern and waits for the meaning or new steps to emerge from it (Gendlin, 1996).

Felt sense refers to an implicitly complex and not yet conceptually clear bodily felt whole of a person, situation, or event, which encompasses everything one feels and knows about the given subject at a given time (Gendlin, $1974,1981)$.

Felt shift describes the stirring or shift of a felt sense when an answer comes directly from the felt sense. This shift is experienced as a distinct physical shift in the bodily sense of the given concern. The problem may or may not be solved, but the way it is carried or experienced in the body is different. There is a sense of easing or release of tension, a sense of fresh air or energy flowing in response to the meaning, steps, or answers that emerge from the process of Focusing (Gendlin, 1981).

\section{Selection of Participants}

The researcher contacted the local Focusing center for 
a list of potential participants. The list of potential participants included people who have participated in the Experiential Focusing training offered by the Focusing center and expressed interest in Focusing dream work. The potential participants' involvement in the Focusing center did not constitute a counseling relationship and consequently was not subject to the limits of confidentiality. The director of the Focusing center supplied the list of potential participants to the researcher who contacted the potential participants directly. The researcher selected participants on the basis of their ability to recall one or more dreams per week. The first 20 potential participants who met the criterion and who consented to participate became the participants of this study. No exclusion was made on the basis of age, gender, ethnicity, or disability. However, an effort was made to match for participants' experience with formal training in dream work.

Participants signed an informed consent form (Appendix B). The researcher assured verbally and in writing of the confidentiality of the information they were going to disclose in the study. She also assured them of their right not to respond to any question that seemed intrusive to 
their privacy and to discontinue participation at any time.

\section{Intervention}

The intervention consisted of a 45-minute Focusingoriented dream interpretation session guided by the researcher. A guided Focusing session refers to a Focusing session with a partner who exhibits ability for empathic listening and Focusing process suggestions. A Focusing session is successful when a felt shift occurs. This can happen with or without a partner. However, based on observations made by this researcher, a Focuser is more likely to have a successful Focusing session with a partner than without one.

Gendlin (1986) emphasized the need to check and control for the presence of the intervention in an experimental-control research design. In this study, the presence of the intervention was maximized by an experienced Focusing guide guiding the Focusing dream interpretation session.

The researcher acted as Focusing guide for all research participants. She had a master's degree in Counselor Education and was working toward completion of her doctoral training in Counselor Education. She had formal training in Focusing and Focusing-oriented dream 
work. The researcher had 11 years of experience as a Focuser and had co-facilitated Focusing training and workshops with a certified Focusing trainer.

\section{Instrumentation}

Two instruments were used in this study: the Dream Interpretation Effects Questionnaire (DIEQ) and a structured interview designed by the researcher. The researcher used the DIEQ (Appendix F) to collect information regarding the effects of dream interpretation. Other questions (Appendix G) included in the structured interview offered research participants an opportunity to clarify, elaborate on, or comment on their experience during the study. The Dream Interpretation Effects Questionnaire

Development of the Dream Interpretation Effects Questionnaire. The researcher developed the DIEQ to meet the purpose of this study. The DIEQ consisted of a cover page and three parts. Both quantitative and qualitative data were gathered through the cover page, Part Two, and Part Three of the DIEQ. By contrast, only quantitative data were gathered through Part one of the DIEQ.

The cover page addressed information on preexisting factors that may influence research participants' 
experience with this study. Part one of the DIEQ assessed major effects of Focusing-oriented dream interpretation, whereas Part Two of the DIEQ gathered in-depth information regarding the same phenomena. Part Three of the DIEQ assessed if differences existed in the participants' view of the meaning of their dreams before and after dream interpretation as well as their reactions to the process. Three versions of Part Three of the DIEQ were developed to match for the participants' status as either an experimental group or a control group participant as well as their experience in different phases of the research process. The cover page, Part One, and Part Two of the DIEQ were used as pretest, whereas Part One, Part Two, and Part Three of the DIEQ were used as posttest in this study for both the experimental and control groups. The following text summarized the origin and purpose of the items included in the DIEQ.

Items in the cover page of the $D I E Q$ addressed information on preexisting factors that may influence participants' experience with this study. Items 1, 2, 3, 4, and 5 in the cover page reflected participants' dernographic data. Items $6,7,8$, and 9 reflected information concerning participants' dream Iife and dream recall frequency. Items 
10 and 11 reflected participants existing attitude toward dreams, previous experience with dream interpretation, and expectation toward this study. Item 12 assessed the length of the dream the participants chose to use in this study. This item was included to examine any possible relationship between the length of a dream and the effects of dream interpretation.

Part One of the DIEQ was previously described in this dissertation in the preceding section entitled First part of the Study: Development of Part one of the DIEQ. Part Two of the DIEQ addressed in-depth information regarding the major effects of Focusing-oriented aream interpretation via both Likert scales and open-ended questions. As reviewed in Chapter I, dream interpretation theorists hold different perspectives regarding what self knowledge can be gained through dream work. In Part Two of the DIEQ, items were included to reexamine 1) theoretical assumptions of various dream interpretation theories, 2) existing research findings of dream interpretation, and 3) results specific to Experiential Focusing.

Part Two of the DIEQ consisted of 24 items. These items were divided into six categories based on their origins and purpose. The first category consisted of items 
$1,2,19,20$, and 24 . These items were non-theory specific questions that assessed participants' opinions about the general effects of dream interpretation. The second category consisted of items 12,13 , and 21 . These items reflected Freudian theory of dream interpretation that dreams disguise repressed or unfulfilled wishes and sexual feelings. The third category consisted of items 10, 11,14 , and 17. These items reflected Jungian theory that dreams compensate for the ego's limited view of self identity to include the rejected, undeveloped, or the transpersonal aspects of self. The fourth category consisted of items 8 and 9. These items reflected Gestalt theory that dreams reflect projected parts of the personality, with the emphasis on bringing into awareness and integrating the disowned parts of the personality. The fifth category consisted of items $3,15,16,18,22$, and 23. These items reflected Focusing related effects of dream interpretation that include felt sense, quality of felt energy, insight into new direction, healing or reconciliation, and certainty of the emerged meaning of the dream. The sixth category consisted of items 4, 5, 6, and 7. These items reflected empirical findings that suggested dreams reflect current or past concerns and serve a function of problem- 
solving.

Part Three of the DIEQ assessed if differences existed in the participants' view of the meaning of their dreams before and after dream interpretation as well as their reactions to the process. Items 1,2 , and 7 assessed change in the participants' experience of the meaning of their dreams in the process. Item 3 assessed change in the participants' attitude toward dreams in general. Items 4 , 5, and 6 assessed participants' evaluation of the helpfulness of dream interpretation and the degree to which their expectations were fulfilled by the process. Reliability and Validity of the Dream Interpretation Effects Questionnaire. Reliability for Part one of the DIEQ was established through the examination of its internal consistency by Cronbach alpha (Cronbach, 1951) for the instrument as a whole and for each of the seven categories. For the purpose of this study, a Cronbach alpha of .80 or higher was considered reliable, .65 - .79 marginally reliable, and .64 or lower unreliable. Reliability regarding the rest of the DIEQ was not considered at this point because its purpose was similar to that of a qualitative study: to gather in-depth information regarding the focus of the study. Content validity for the DIEQ was 
established through the support of the existing professional literature.

Structured Interview

A structured interview was used so that greater depth of information could be obtained (Heppner et al., 1992). The interview followed an interview schedule (Appendix G) that contained questions that encourage participants to clarify, elaborate on, and make comments on their previous responses.

\section{Research Design and Procedures}

A pretest-posttest control group design was used in the second part of this study. A combination of quantitative and qualitative data were gathered through the DIEQ and a structured interview. Volunteer participants who met the established criteria of selection were randomly assigned to an experimental group and a waiting-list control group.

In the first phase of this part of the study, both the experimental and control group participants began by describing their areams to the researcher in the present tense and in as much detail as possible. Participants in both groups then completed the DIEQ (pretest). The experimental group participants then had a researcher- 
guided Focusing dream interpretation session on the dream they had described. By contrast, the control group participants engaged in personal activities irrelevant to dream work during a 45-minute no-intervention waiting period. The participants in both groups then completed the DIEQ again (posttest). This posttest outcome was referred to as posttest for experimental group participants and first posttest for control group participants.

In the second phase of this part of the study, immediately following completion of the first posttest, the control group participants went through the Focusing dream intexpretation intervention and again completed the DIEQ (second posttest). The control group's first and second posttest data were analyzed to strengthen the results (Heppner, Kivlighan, Wampold, 1992). Participants in the experimental group participated in a structured interview after the posttest, whereas participants in the control group participated in a structured interview after the second posttest.

Notationally, the design can be conceptualized as follows : 


\section{$\begin{array}{lllllll}x_{1} & \mathrm{Oe}_{2} & \mathrm{x}_{2} & \mathrm{Oe}_{2} & \mathrm{SI}\end{array}$ \\ $R$ Con group: $\begin{array}{lllllll}x_{1} & O c_{1} & O c_{2} & x_{2} & O c_{3} & S I\end{array}$}

R: random assignment of participants to experimental or control group

$\mathbf{x}_{1}$ : dream report intervention

$\mathbf{x}_{\mathbf{2}}$ : Focusing intervention

Oe ${ }_{1}$ : pretest for experimental group

Oe ${ }_{2}$ : posttest for experimental group

Oc 1 pretest for control group

Oc $c_{2}$ : first posttest for control group after waiting-period

Oc $c_{3}$ second posttest for control group after

Focusing intervention

SI: structured interview

\section{Limitations}

The second part of this study has the following limitations :

1) The number of participants in both the experimental group and control group was small, and the participants 
were not matched for age, gender, race, or socio-economic or educational status.

2) The research results may suffer a lack of generalizability because of the use of volunteer participants.

3) The DIEQ is not well established but rather a new instrument developed specifically for the purpose of this stucy.

4) The instrument used in this research relies on self-report. This may lend itself to distortions by the participants. According to Heppner et al. (1992), participants may respond consciously or unconsciously in ways that do not reflect their experience when self-report is used as the source of information.

5) Another limitation of this study lies in the fact that the researcher and the author of this study are the same person. According to Heppner et al. (1992), the adoption of an experimental-control group design, the use of standardized research procedure, and the use of objective measures are strategies that can be used to minimize researcher bias. The researcher followed their suggestions to minimize the possibility of researcher bias in this study. 
6) Generalizability is limited by the use of participants who were experienced in Focusing. Such participants may have been predisposed to benefit from and report positively on the Focusing method used. Collection of Data

Volunteer participants who met the criteria for selection were randomly assigned to either an experimental or a control group. The experimental group participants filled out the DIEQ before (pretest) and after (posttest) the guided dream interpretation session, whereas the control group participants filled out the DIEQ before (pretest) and after (first posttest) the waiting period and again after (second posttest) a guided dream interpretation session. Pretest was defined for both experimental and control group participants as testing the effects of merely reporting and associating on the dream. Posttest was defined for the experimental group participants as testing the effects of Focusing-oriented dream interpretation. First posttest was defined for the control group participants as testing the effects of a 45-minute nointervention waiting period and second posttest was defined as testing the effects of subsequent Focusing-oriented dream interpretation. 
The information gathered from the cover page of the DIEQ and the structured interview constituted the qualitative data, whereas the information from Part one, Part Two, and Part Three of the DIEQ constituted both the quantitative and qualitative data of the study. Field notes were also taken on additional observations and comments made by the researcher or the participants. In addition, the researcher asked for the research participants' permission to audiotape their dreams for the purpose of analyzing the qualitative data of this study.

\section{Analysis of Data}

The data from Part one of the DIEQ was keyed into the computer and analyzed using SPSS for MS Windows Release 6.0 (Norusis, 1994). T-test for independent or dependent samples was computed to test the significance of the difference between 1) the pretest mean and posttest mean of the experimental group participants, 2) the pretest mean and first posttest mean of the control group participants, 3) the mean difference between pretest and posttest for experimental and control group participants, and 4) the first posttest mean and the second posttest mean of control group participants. A significance level of .01 was established as the criterion for either retaining or 
rejecting the null hypotheses to minimize the Type I error rate for this study. Responses from open-ended questions and structured interview as well as observations and comments from field notes were examined to note any themes or patterns within or among participants or between groups. 
CHAPTER III

RESULTS AND DISCUSSION

This chapter presents the results of the analysis of the data and a discussion of the findings, implications, and recommendations for further research.

Results

Findings Regarding the Reliability of the Dream

Interpretation Effects Questionnaire

Research Hypothesis 1

A preliminary instrument with validity and with reliability at . 80 level or higher can be developed to assess seven effects of Focusing-oriented dream interpretation.

Fifty-two students from four graduate classes at the University of North Texas voluntarily participated in the first part of this study. Table 1 presents the results of the measure of reliability for Part one of the DIEQ. Internal consistency of the total DIEQ and the seven categories of major effects of Focusing-oriented dream interpretation was assessed by a Cronbach alpha. Internal 
consistency for the seven categories ranged from .80 to .93 with internal consistency for the total questionnaire measuring .96. For the purpose of this study, a Cronbach alpha of .80 or higher was considered reliable. As a result, all 52 items were retained and included in the final instrument.

Table 1

Reliability Analysis of the DIEQ

$\mathrm{N}$ of cases $=52$ $\mathrm{N}$ of items Mean $\underline{\text { Range }}$ Cronbach alpha

$\begin{array}{lcccc}\text { category one } & 6 & 3.53 & 0-6 & .91 \\ \text { category two } & 8 & 4.12 & 0-6 & .80 \\ \text { category three } & 7 & 3.39 & 0-6 & .92 \\ \text { category four } & 8 & 3.08 & 0-6 & .90 \\ \text { category five } & 7 & 2.91 & 0-6 & .86 \\ \text { category six } & 9 & 5.04 & 0-6 & .91 \\ \text { category seven } & 7 & 3.39 & 0-6 & .93 \\ \text { total } & 52 & 3.69 & 0-6 & .96\end{array}$

Findings Regarding the Effects of Experiential

Focusing-oriented Dream Interpretation

Twenty-two potential participants were contacted 
through a local Focusing center. Two declined the invitation because of time constraints. Twenty accepted the invitation and participated in the second part of this study. All participants were randomly assigned to either an experimental or a control group, with 10 participants in each group.

The results regarding the effects of Experiential Focusing-oriented dream interpretation are presented in the order that the research hypotheses and question were tested or examined. As previously stated, a t-test for independent samples was performed on research hypothesis 4 and a t-test for dependent samples was performed on research hypotheses 2, 3, and 5. In order to reduce the Type I error rate associated with the use of multiple t-tests, a significance level of .01 was established as the criterion for either retaining or rejecting the null hypotheses. The Type I error rate was .04 for this study.

Research Hypothesis 2

Participants in the experimental group will attain a significantly higher mean score on posttest than on pretest as indicated by Part one of the DIEQ. 
The null and alternate hypotheses were as follows:

$$
\mathrm{H}_{0}: u_{1}-u_{2} \leq 0 \quad \mathrm{H}_{\mathrm{a}}: u_{1}-u_{2}>0
$$

A one-tailed t-test for dependent samples was used to compute the test statistic. Table 2 presents the pretest and posttest means for experimental group participants, standard deviations, t-value, degrees of freedom, and level of significance.

The result shows that the null hypothesis was rejected in favor of the directional alternative hypothesis at the .001 level of significance. On the basis of these data, research hypothesis 2 was retained.

Table 2

T-test of pretest and posttest DIEQ scores for experimental group

\begin{tabular}{lcccr}
\hline & $\underline{\text { Mean }}$ & $\underline{\mathrm{SD}}$ & $\underline{\mathrm{t}}$ & $\underline{\mathrm{df}}$ \\
pretest & 96.90 & 66.86 & $9.93^{* * *}$ & 9 \\
posttest & 306.60 & 14.01 & &
\end{tabular}

$* * * p<.001$

Note. $n=10$ 
Research Hypothesis 3

Participants in the control group will attain no significantly higher mean score on first posttest than on pretest as indicated by Part one of the DIEQ.

The null and alternate hypotheses were as follows:

$$
H_{0}: u_{1}-u_{2}=0 \quad H_{a}: u_{1}-u_{2} \neq 0
$$

A two-tailed t-test for dependent samples was used to compute the test statistic. Table 3 presents the pretest and first posttest means for control group participants, standard deviations, t-value, degrees of freedom, and level of significance.

Table 3

T-test of pretest and first posttest DIEQ scores for control group

\begin{tabular}{llllr}
\hline & Mean & $\underline{\text { SD }}$ & $\underline{\mathrm{t}}$ & $\underline{\mathrm{df}}$ \\
pretest & 99.70 & 42.79 & .095 & 9 \\
1st posttest & 99.80 & 42.64 & & \\
\hline
\end{tabular}

Note. $n=10$

The result shows that the null hypothesis was not rejected in favor of the alternative hypothesis. On the 
basis of these data, research hypothesis 3 was retained. Table 4

T-test of difference between pretest and posttest DIEQ scores for experimental and control group

\begin{tabular}{lrccc}
\hline & Mean & $\underline{\mathrm{SD}}$ & $\underline{\mathrm{t}}$ & $\underline{\mathrm{df}}$ \\
experimental group & 209.70 & 66.80 & $9.91 * \star \star$ & 18 \\
control group & .10 & 3.31 & &
\end{tabular}

$* * *_{p}<.001$

Note. $n=10$ in each group

Research Hypothesis 4

The mean difference between posttest and pretest scores for experimental group participants will be greater than the mean difference between first posttest and pretest scores for control group participants as indicated by Part One of the DIEQ.

The null and alternate hypotheses were as follows:

$$
\mathrm{H}_{0}: u_{1}-u_{2} \leq 0 \quad \mathrm{H}_{\mathrm{a}}: u_{1}-u_{2}>0
$$

A one-tailed t-test for independent samples was used to compute the test statistic. Table 4 presents the mean difference between pretest and posttest for experimental 
and control group participants, standard deviations, tvalue, degrees of freedom, and level of significance. The result shows that the null hypothesis was rejected in favor of the directional alternative hypothesis at the .001 level of significance. On the basis of these data, research hypothesis 4 was retained.

Table 5

T-test of first posttest and second posttest DIEQ scores for control group

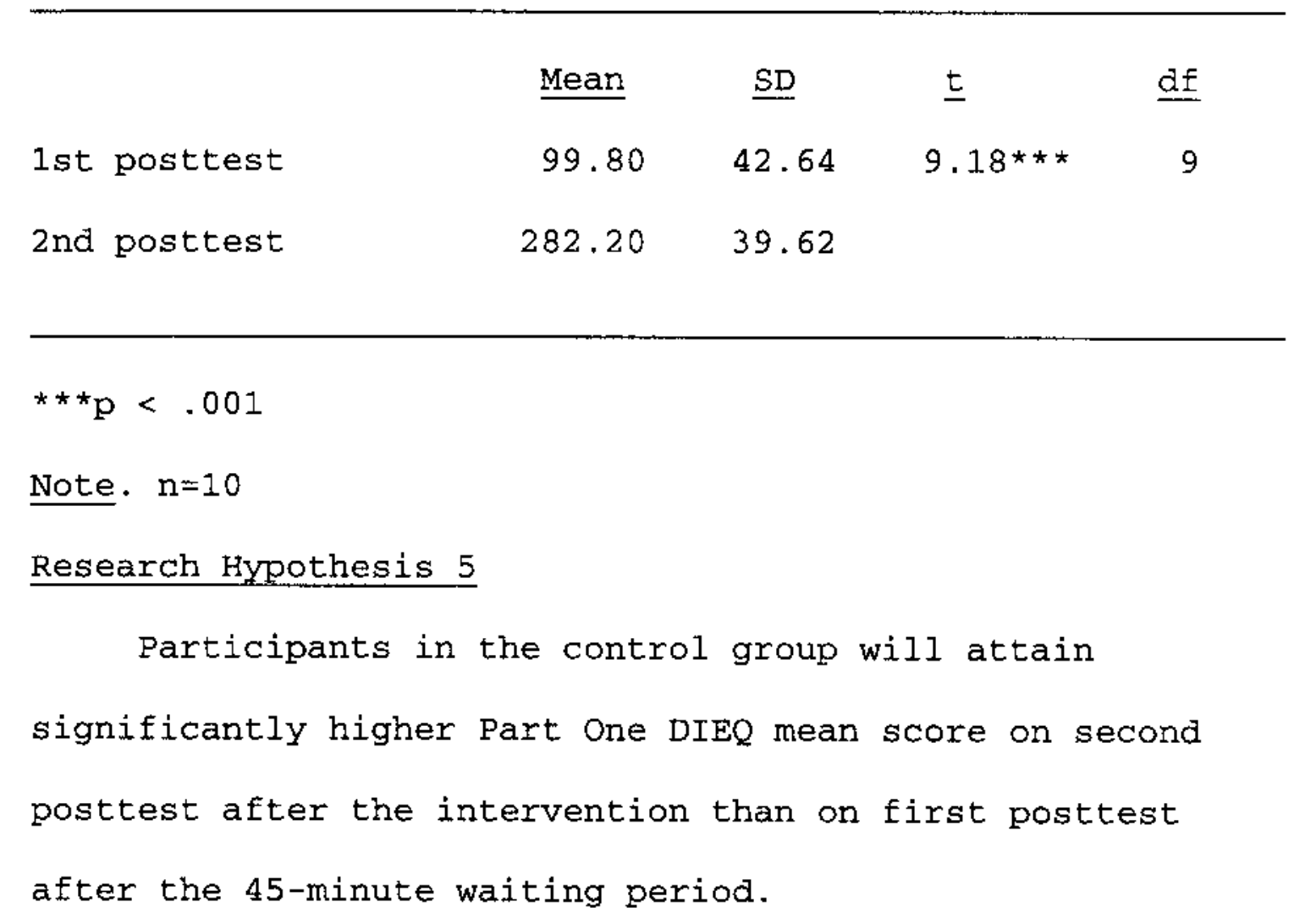


The null and alternate hypotheses were as follows:

$$
\mathrm{H}_{0}: u_{1}-u_{2} \leq 0 \quad \mathrm{H}_{\mathrm{a}}: u_{1}-u_{2}>0
$$

A one-tailed t-test for dependent samples was used to compute the test statistic. Table 5 presents the first and second posttest means for control group participants, standard deviations, t-value, degrees of freedom, and level of significance.

The result shows that the null hypothesis was rejected in favor of the directional alternative hypothesis at the .001 level of significance. On the basis of these data, research hypothesis 5 was retained.

\section{Research Question}

Are there observable patterns in the qualitative data gathered in this study through the Cover Page, Part Two, and Part Three of the DIEQ and the structured interview? Findings regarding the Cover Page of the DIEQ. Table 6 presents a summary of the participants' background information and other preexisting factors of the participants. Included in the table, (8) length of the dream came from item 12 of the Cover Page. This item represented an evaluation of the relative length of the dream from "0" to "6" by the research participants. The 
length of the dream is short when the ratings of the participants were "0", "1", or "2", medium when the ratings were " 3 " or "4", long when the ratings were "5" or "6".

Table 6

Background information of the research participants

experimental control total

group group

$\begin{array}{rrrr}\text { (1) gendex: male } & 2 & 1 & 3 \\ \text { female } & 8 & 9 & 17\end{array}$

(2) age: 20's

$\begin{array}{lll}0 & 1 & 1\end{array}$

$\begin{array}{llll}30 ' \mathrm{~s} & 3 & 7 & 10\end{array}$

$\begin{array}{llll}40 ' \mathrm{~s} & 4 & 2 & 6\end{array}$

$\begin{array}{llll}50^{\prime} \mathrm{s} & 2 & 0 & 2\end{array}$

$\begin{array}{llll}60^{\prime} s & 1 & 0 & 1\end{array}$

(3) marital single

$1 \quad 6 \quad 7$

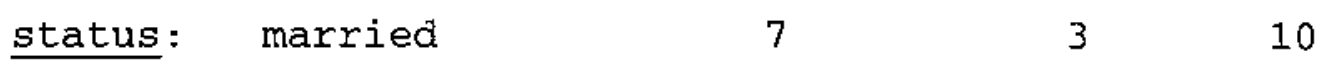

$\begin{array}{llll}\text { divorced } & 2 & 0 & 2\end{array}$

$\begin{array}{llll}\text { widowed } & 0 & 1 & 1\end{array}$



(4) educational
undergraduate 3
2
5 level:
građuate
7
8
15

(5) ethnic Asian, Asian American 2

$5 \quad 7$

group: Caucasian

7

4

11

other (bi-racial)

1

1

2

(6) dream recall frequency:

1-3 per night

(7) pre

previous experience of yes

6

12

dream interpretation: no 4

4

8

$\begin{array}{lllll}\text { (8) length of } & \text { short } & 5 & 4 & 9 \\ \text { the dream: } & \text { medium } & 4 & 4 & 8 \\ & \text { long } & 1 & 0 & 1\end{array}$

As illustrated in Table 6 , because of the uneven size of each category, further statistical analysis could not be performed on the participants' background information. However, an overall assessment by this researcher suggests that research participants' gender, age, marital status, educational level, ethnicity, previous experience with dream interpretation, and length of the dream did not 
contribute to any significant difference in the outcome of this study.

Findings regarding Part Two and Part Three of the DIEQ, with references to Part one of the DIEQ and the structured interview. Findings regarding the rest of the quantitative and qualitative data gathered in this study were examined against the outcome of Part one of the DIEQ and structured interview. This information is presented in the order of, and with references to, the seven major effects of Focusing-oriented Dream Interpretation.

To examine in detail the effects of Focusing-oriented dream interpretation, a category by category analysis of the seven major effects was performed. Posttest of the experimental group participants and the second posttest of the control group participants were combined together to compare with the combined pretest outcome of both the experimental and control group participants. Tables 7,8 , $9,10,11,12$, and 13 present pretest and posttest means and test statistics for the seven major effects of Focusing-oriented dream interpretation from Part one of the DIEQ. Each table is then followed by a summary of the detailed accounts of the same phenomenon by research participants, which was derived from Part Two and Part 
Three of the DIEQ and the structured interview.

As illustrated in Tables 7 and 8 , the results in terms of the first and second effect of Focusing-oriented dream interpretation show that the Part one DIEQ mean score on posttest after intervention was significantly higher than the Part One DIEQ mean score on pretest for all research participants.

Table 7

Mean scores and test statistic for major effect (1) a sense of easing or release of tension associated with the dream

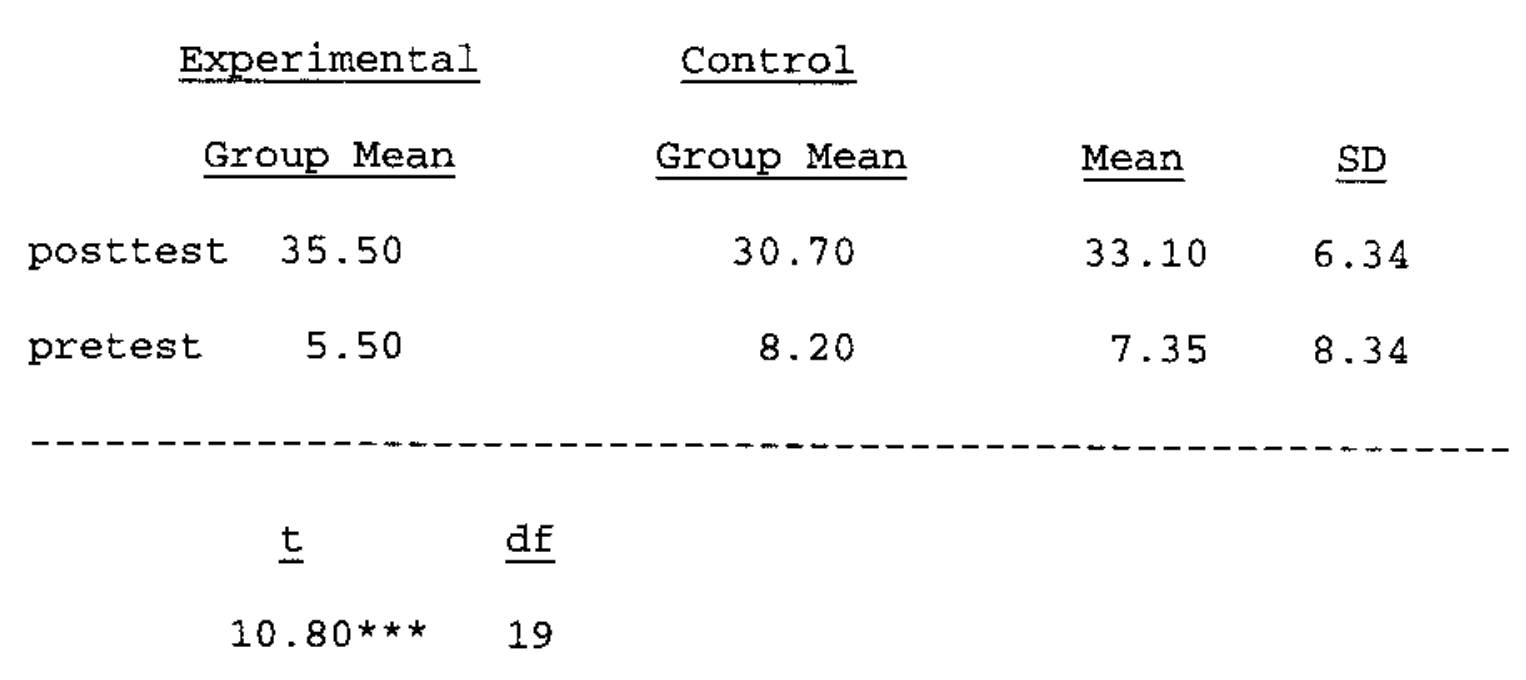

$* * * \mathrm{p}<.001$

Note. $\mathrm{n}=10$ in each group

The corresponding qualitative responses from item 3 of Part Two of the DIEQ mirrored the quantitative finding. 
Participants used neutral or negative descriptive words on pretest to describe their feelings related to the aream, e.g., unclear, uncertain, a sense of uneasiness, confused, tensed, hard to breath, sad, feel like crying, stressed, mixed feelings, anxious, scared, fearful, threatened, frustrated, stuck, or low in energy.

Table 8

Mean scores and test statistic for major effect (2) a sense of Eresh air or increase of positive energy associated with the dream

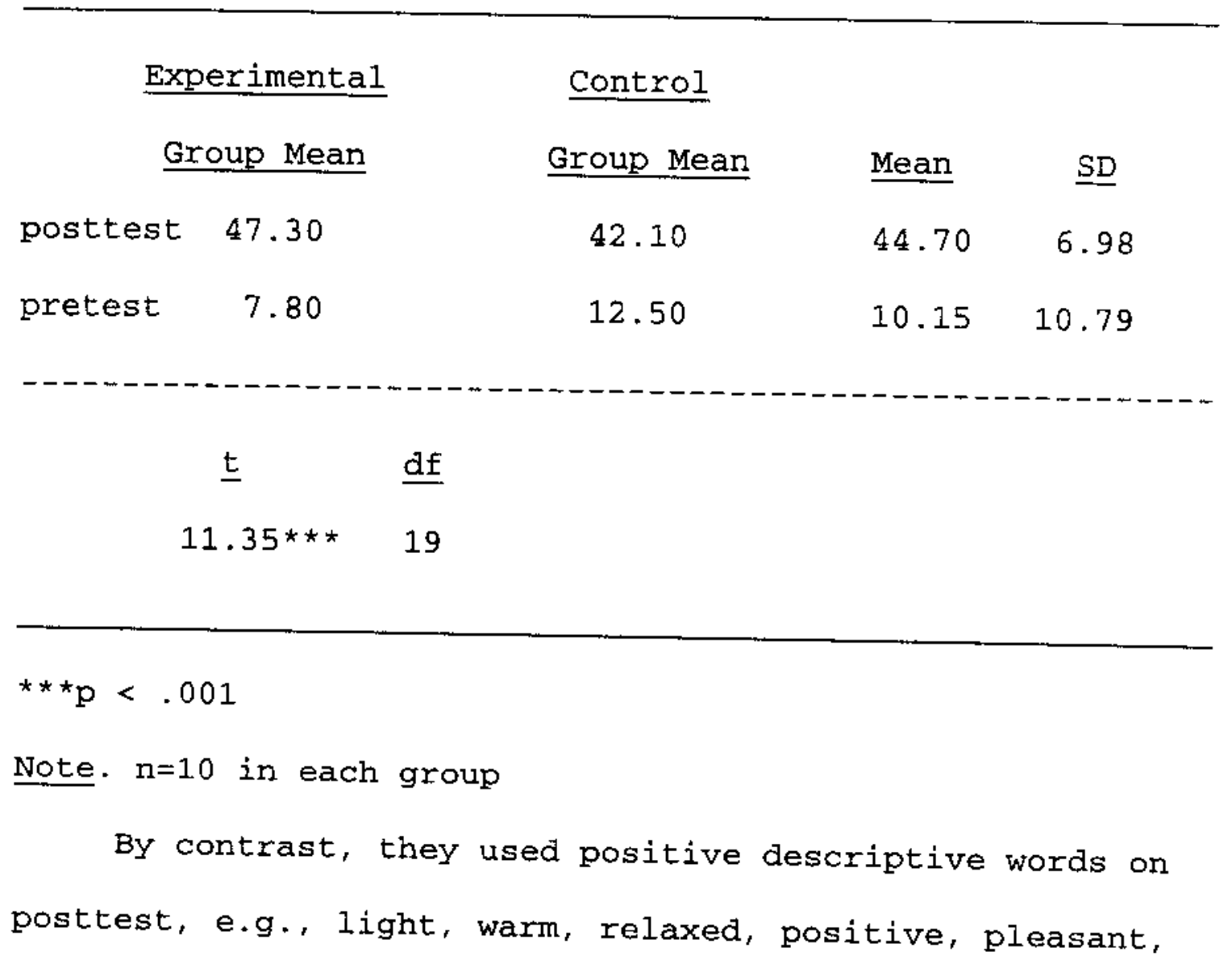


relieved, liberated, a sense of fresh air, peaceful, centered, connected, a sense of more whole, excited, hopeful, joyful, strong, empowered, freeing, a sense of energy flowing, alive, energized, full of energy, loved, loving, or a sense of spiritual connection.

Table 9

Mean scores and test statistic for major effect (3) increased self understanding

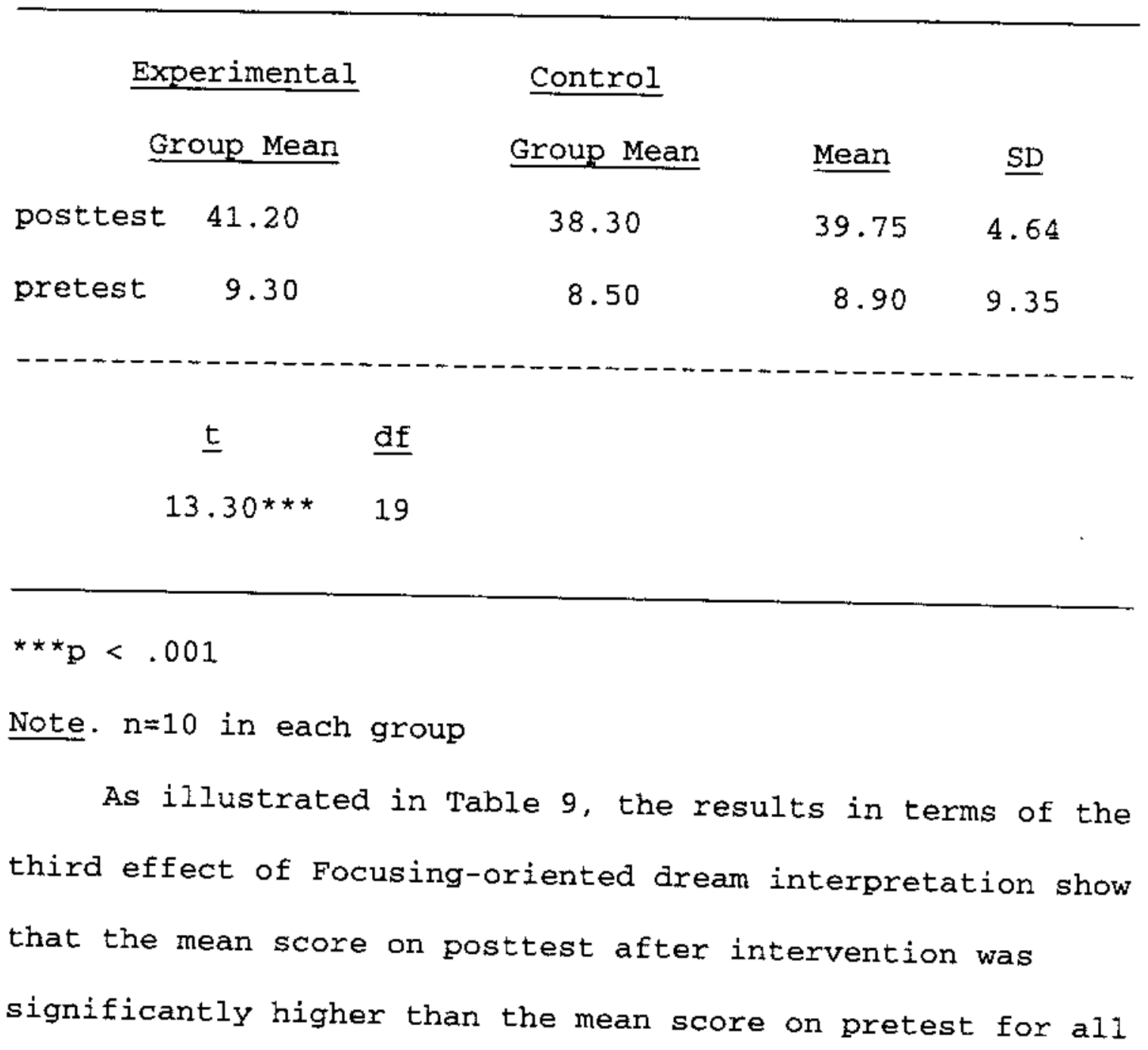


research participants as indicated by Part one of the DIEQ.

The corresponding responses from items 4, 6, 8, 9, 10 , $11,12,13,14,15$, and 17 of Part Two of the DIEQ also showed that the overall posttest scores were higher than the pretest scores for all participants. As a result of the intervention, all participants reported having experiences of increased awareness or understanding toward various aspects of themselves.

Table 10

Mean scores and test statistic for major effect (4) a sense of movement, reconciliation, or healing




the fourth effect of Focusing-oriented dream interpretation show that the mean score on posttest after intervention was significantly higher than the mean score on pretest for all research participants as indicated by Part one of the DIEQ.

The corresponding responses from items $5,7,16$, and 19 of Part Two of the DIEQ also showed that posttest scores were higher than the pretest scores for all participants. As a result of the intervention, all participants reported having experiences of a change of perception, of some movement toward resolution of a concern, or of a sense of reconciliation or healing. However, three of the 10 experimental participants and one of the 10 control participants responded "not applicable" to item 7. It was reportedly because the dream did not reflect an unresolved issue from the past for these participants.

As illustrated in Table 11, the results in terms of the fifth effect of Focusing-oriented dream interpretation show that the mean score on posttest after intervention was significantly higher than the mean score on pretest for all research participants as indicated by Part one of the DIEQ. The corresponding responses from item 18 of Part Two of the DIEQ also showed that the overall posttest scores were higher than the pretest scores for 17 of the 20 
participants. However, the pretest scores and posttest scores were all "six", the highest possible score, for two of the 10 experimental participants and one of the 10 control participants, indicating a ceiling effect.

Table 11

Mean scores and test statistic for major effect (5)

development of a new step or new direction regarding a concern

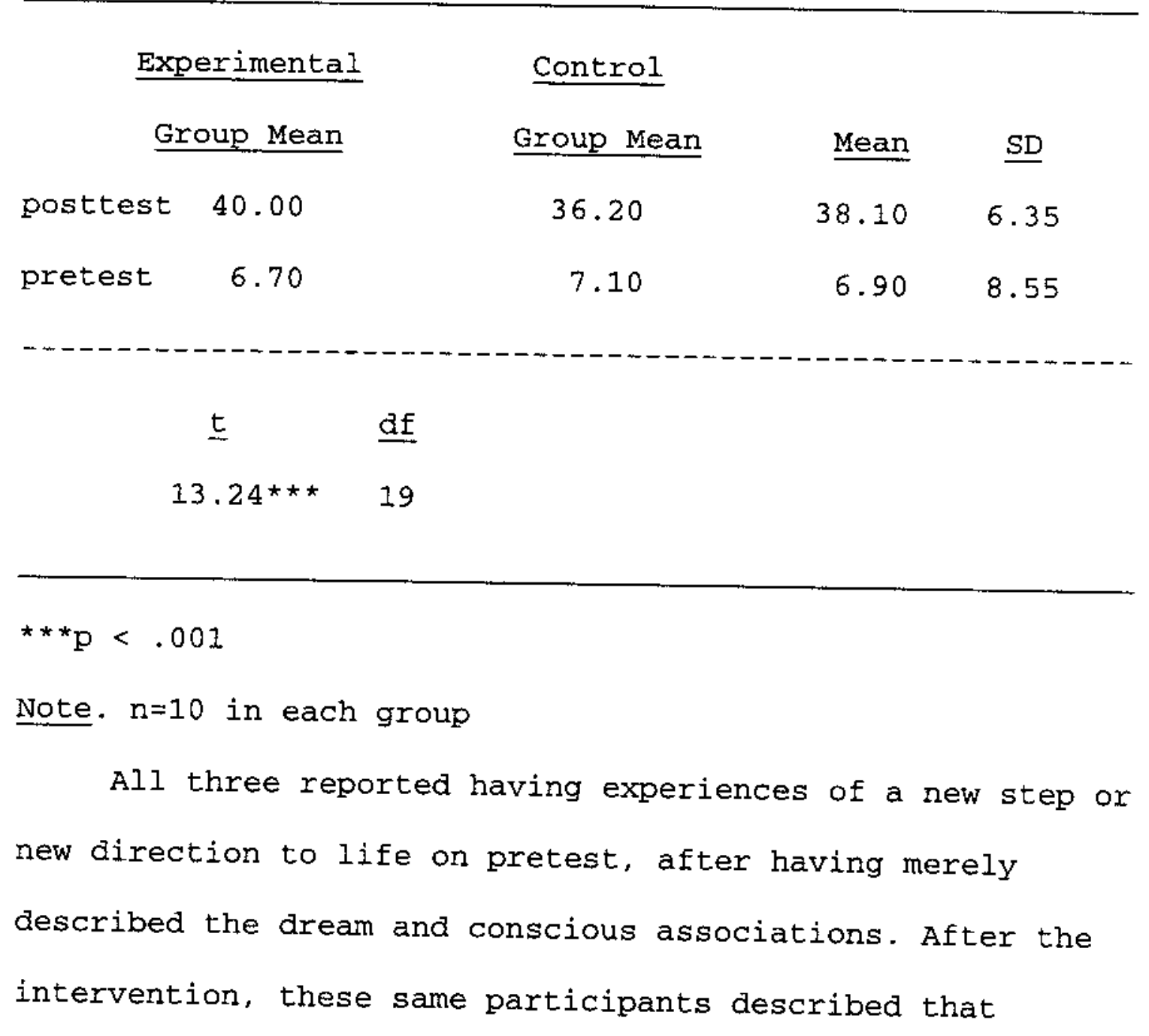


Focusing dream interpretation deepened their experiences of the meaning of the dream and the new step or new direction was experienced at a bodily level. This suggests that as a result of the intervention, all participants had experiences of a new step or new direction in life, although due to ceiling effect, the quantitative scores did not show a difference in 3 cases.

Table 12

Mean scores and test statistic for major effect (6) enhanced valuation of dreams

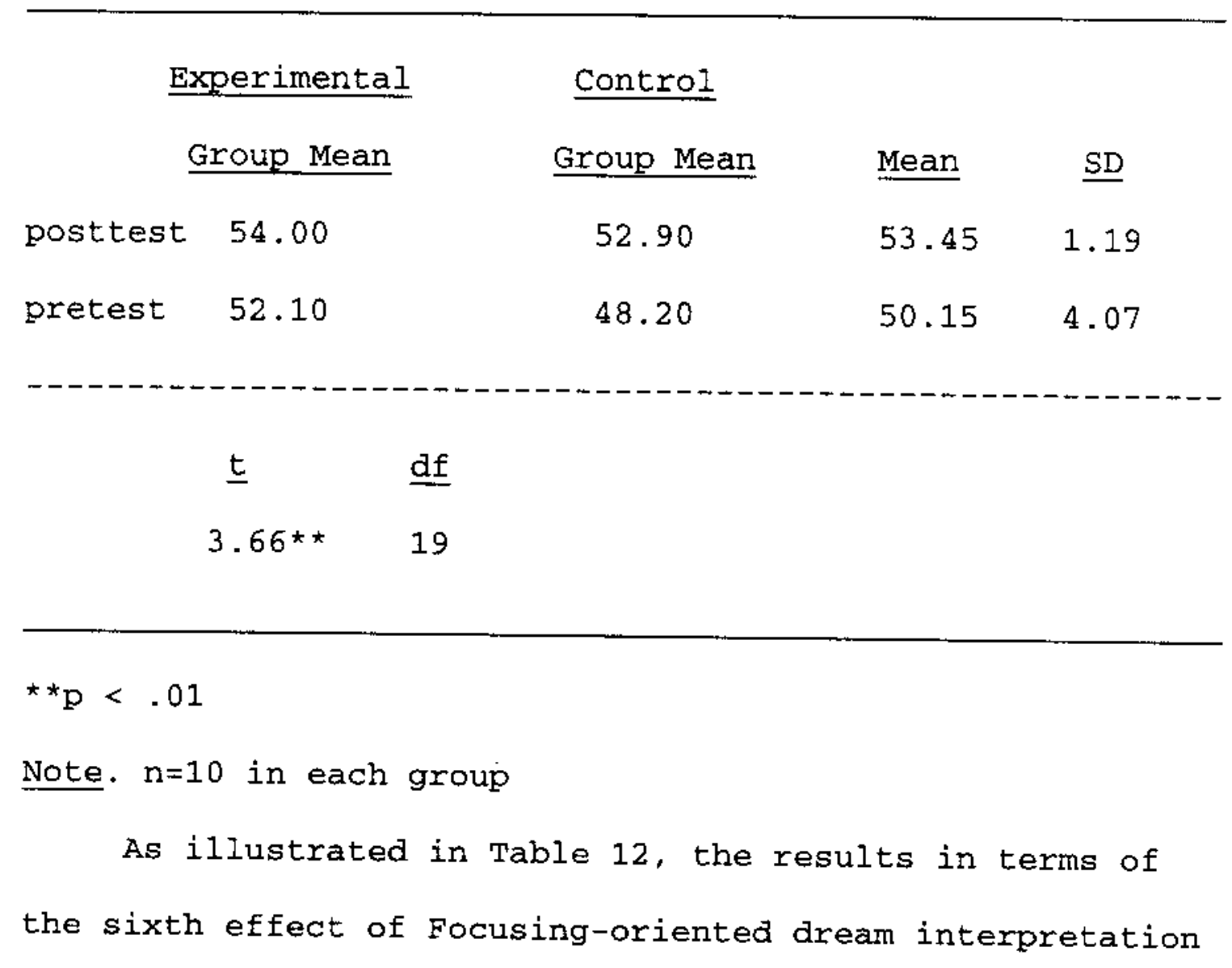


show that the mean score on posttest after intervention was significantly higher than the mean score on pretest for all research participants as indicated by Part one of the DIEQ. The corresponding responses from item 3 of Part Three of the DIEQ also showed that posttest scores were higher than the pretest scores. However, the differences were not as significant as other effects. All participants reported high evaluation of dreams from the beginning. As a result of the intervention, all participants reported having even deeper appreciation of the value of dreams and dream work. As illustrated in Table 13, the results in terms of the seventh effect of Focusing-oriented dream interpretation show that the mean score on posttest after intervention was significantly higher than the mean score on pretest for all research participants as indicated by Part One of the DIEQ.

The corresponding responses from item 1 of Part Three of the DIEQ also showed that posttest scores were higher than pretest scores. As a result of the intervention, all participants experienced profoundly enhanced understanding of the meaning of the dream. 
Table 13

Mean scores and test statistic for major effect (7) enhanced understanding of the meaning of the dream

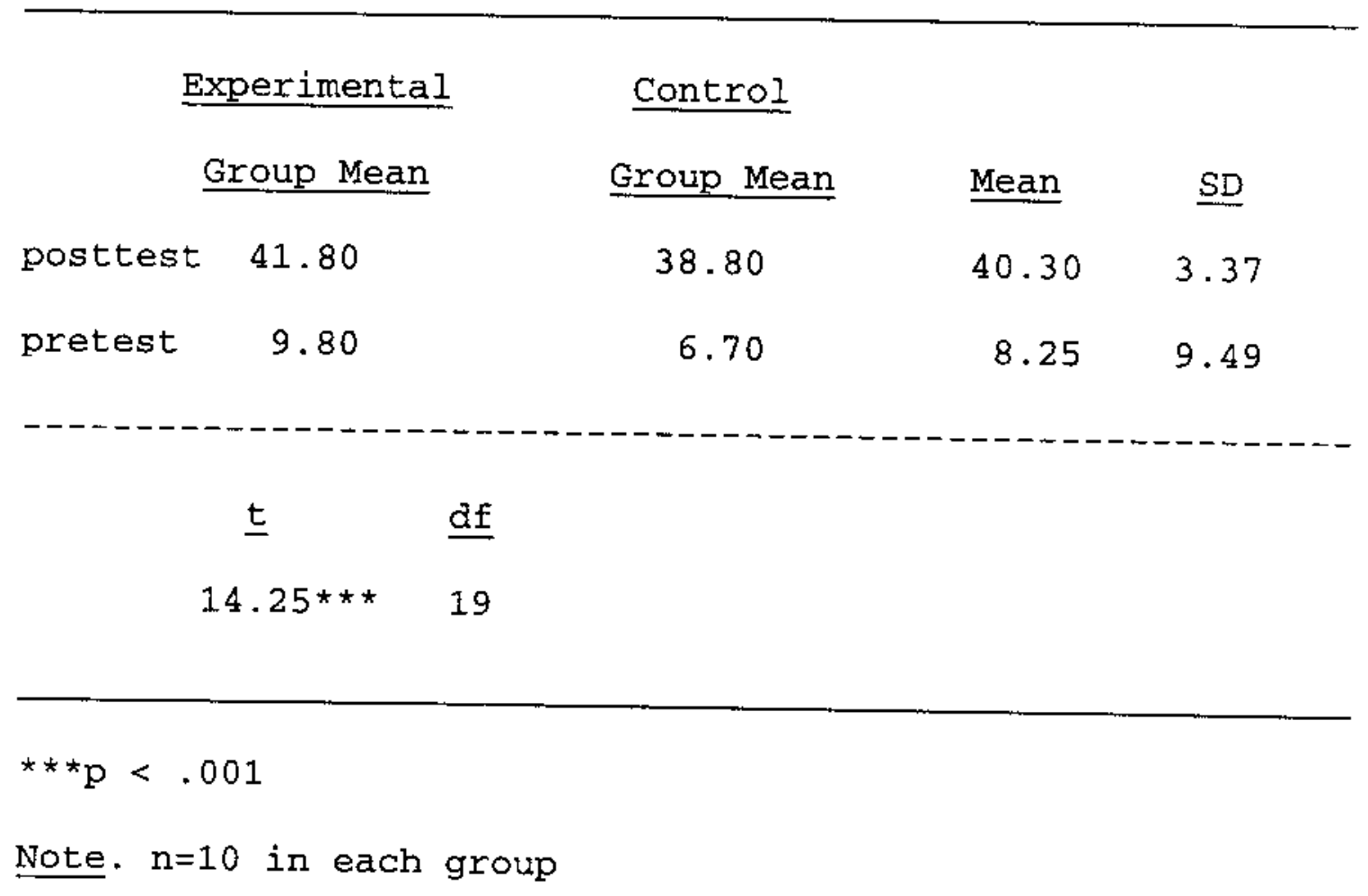

Furthermore, as indicated by the responses from item 1, 2, and 7 of Part Three of the DIEQ, al1 participants reported a profound change in their understanding of the meaning of the dream after the intervention. They also reported that Focusing deepened the meaning of the dream. for them.

Lastly, as indicated by items 4,5 , and 6 of Part Three of the DIEQ, all participants described the intervention as helpful and were eager to use Focusing 
dream interpretation in the future.

$$
\text { Discussion }
$$

The results of this study illustrated many aspects of the effects of Experiential Focusing-oriented dream interpretation. Significant results were found on the research question and all research hypotheses were retained.

From the most statistically conservative point of view, the ordinal data obtained through the use of Likert scales in this study could be considered most appropriately analyzed with nonparametric tests. The researcher performed nonparametric tests on all research hypotheses to see if similar results could also be found with nonparametric tests. The wilcoxon matched-pairs signed-rank test was performed on research hypotheses 2, 3, and 5, and the MannWhitney $U$ test was performed on research hypothesis 4 . The results showed that all research hypotheses were retained at .01 level of significance. This result showed that $t-$ test and nonparametric tests resulted in equivalent results.

The results of this study have several implications. They are discussed as follows. 
A Preliminary Instrument with Validity and Reliability can be Developed to Assess the Seven Effects of FocusingOriented Dream Interpretation

According to the findings of the first part of this study, the DIEQ can be preliminarily regarded as a reliable instrument that assesses seven effects of Focusing-oriented aream interpretation. All 52 items of Part one of the DIEQ were retained in this study. This decision was made on the basis of the relatively high Cronbach alpha coefficients and also on the basis of the consulting statistician's suggestion that more items tend to generate higher statistical power.

However, several research participants commented on the redundancy of several of the items and reported fatigue associated with having had to respond to a long questionnaire. This suggests a need for further study to take the next step in more stringent analysis used in the development of an instrument, e.g., assess which items from each category can be deleted without greatly reducing the Cronbach alpha coefficient for the category. Focusing-Oriented Dream Interpretation Showed Significant Results

According to the findings of the second part of this 
study, the posttest after intervention for all research participants showed a significant increase in the seven effects of Focusing-oriented dream interpretation. The research participants' comments and the researcher's observation also supported this result.

Fourteen of the 20 participants were available for a follow-up telephone interview approximately one week after the research. All 14 participants reported having experiences of some form of application of the insight gained from the research. These applications can be summarized as follows: 1) The participant was able to make further connections, based on the insight gained from the dream work, to understand the underlying causes of one's emotions, thoughts, or behaviors; 2) The participant gained immediate awareness during acting out of an undesired pattern of behavior and was able to respond differently based on the insight gained from the dream work; 3) The participant continued to experience at a bodily felt level a different way to be or to handle a concern; 4) The participant began working or continued to work on the issue reflected by the dream; 5) The participant took actual behavioral steps to carry out the insight gained from the dream; 6) The participant, who had used the Focusing 
attitude during the dream work, realized the value of adopting that attitude to life in general; 7) The participant gained deeper appreciation of dreams and no longer believed in an intellectual approach to dream interpretation; 8) The participant who worked with a negative dream in this study no longer viewed negative dreams as something negative to avoid.

The researcher made several observations about characteristics of participants in the second part of the study. These observations suggest possibly greater generalizability than some of the previously stated Limitations would indicate. First, regarding demographics, participants represented a range in every socioeconomic category and in age, educational level, and marital status; both genders and three ethnic groups were represented. Results did not appear to differ based on these characteristics. In addition, neither amount of previous experience with dream interpretation nor length of the dream appeared to contribute to a difference. Finally, participants' experience in Focusing ranged from nine participants who had had one weekend of training in Focusing to three participants who had two or more years of experience in practicing Focusing. The effects of Focusing- 
oriented dream interpretation appeared to be equivalent for these participants. Although based on preliminary observation rather than statistical analysis, these indications suggest that Focusing-oriented dream work is equally effective and useful for individuals representing a wide range of characteristics.

Gendlin (1981) asserted that anyone can learn and benefit from Focusing. While this may be true, the current study involved only those participants who had experience with focusing. The results of this study strongly suggest that people with Focusing experience, who can remember a dream, and who are guided by someone well-trained in the Experiential Focusing method are highly likely to benefit from Focusing-oriented dream interpretation.

Other Aspects of the Effects of Focusing-Oriented Dream Interpretation

Several themes derived from the qualitative data of this study can be summarized as follows.

1) Focusing-oriented dream interpretation can be used to facilitate positive insight from dreams that include negative emotions. Fifteen of the 20 participants, who reported having experiences of negative feelings associated with the dream on pretest, experienced a significant felt 
shift and positive insight from the dream after the process of Focusing-oriented aream interpretation. This result supported Gendlin's (1986) observation that dreams with negative emotions often evoked a very strong felt sense, and implied in this felt sense are seeds for transformation.

2) Dreams reflect either a current concern or an unresolved issue from the past. All 20 participants reported after Focusing-oriented dream interpretation that their dreams reflected a current concern in their lives. Seventeen of the 20 participants also reported that their dreams reflected an unresolved issue from the past.

3) All participants experienced insight and/or movement regarding an individual need as a result of the Focusing-oriented dream interpretation. Some participants reported having experiences of healing or movement beyond where they felt stuck, whereas others reported gaining awareness of a need to work on a certain issue. All reported that from the process, they got something they had needed. It seems that if healing or movement was what was needed, it was experienced by the participants. By contrast, awareness of a problem or new insight into an unresolved issue tended to emerge from the process when 
that was what was needed.

Many reported that the process showed them something they really needed to see, do, or experience in life or that the dream work touched on a core issue for them. Al1 participants showed an openness to receive what was reflected by their dreams. No participants reacted defensively or with distrust to whatever was reflected by their dreams. This result supported Gendlin's (1981) assertion that what needs to happen will happen in the process of Focusing.

4) The effects were most significant with a strange dream or nightmare. Five of the 20 participants, who described on the pretest that their dreams were scary or strange, reported having experiences of significant transformation after intervention. This dramatic shift happened when participants reported little or no association to or mainly negative associations to the meaning of the dream on pretest. All five participants reported on posttest that their experiences of the meaning of the dream turned into something very positive and even spiritual.

5) Focusing helped research participants reconfirm the meaning of their dream and deepen the insight. All 
participants reported having experiences of one or more felt shifts to reconfirm the meaning of their dreams. Many described that Focusing deepened their experiences of the meaning of the dream.

\section{Summary of Recommendations}

Based on the results of this study, the following recommendations are offered:

1) Furthex study to reconfirm the reliability findings of the DIEQ in this study.

2) Further study that modifies the DIEQ to accommodate potential ceiling effect by adding items that reflect self reported change on posttest.

3) Further study to examine the applicability of the DIEQ to other approaches to dream interpretation.

4) Further study using the DIEQ to compare the relative effectiveness of Focusing with other approaches to dream interpretation.

5) Further study to explore the effects of long term intervention using Focusing-oriented dream interpretation, for example, intervention that consists of eight to 10 sessions.

6) Further study to explore the effects of long term Focusing-oriented dream interpretation on targeted 
populations with specific presenting problems, e.g., depression, eating disorder, or survival of any form of trauma.

7) Further study to explore the effects of short or long term Focusing-oriented dream interpretation on specific types of dreams, e.g., positive dreams, nightmares, recurrent dreams, or mystical dreams.

8) A follow-up study to investigate the long-term effect of Focusing-oriented dream interpretation.

9) Further study to examine the effects of Focusingm oriented dream interpretation with people who are not experienced in Focusing.

10) Further study to compare the effects of Focusingoriented dream interpretation with people who are experienced in Focusing with those who are not.

Conclusion

This study has demonstrated that the effects of Experiential Focusing-oriented dream interpretation can be examined through the use of the DIEQ. According to this study, individuals trained in the use of Focusing and guided by a well trained and experienced Focusing guide tend to be extremely open to examine psychological material reflected by their own dreams. Furthermore, this study also 
strongly suggests that dreams reflect a person's current psychospiritual issues, and Focusing helps the person experience new insight or movement regarding these issues. This finding offers support to Gendlin's proposition that Focusing helps the individual make use of the "clues to and energy for the steps to a solution" (Gendlin, 1996, p. 200) implied in the dream. This specific characteristic of a Focusing approach to dream work implies its therapeutic value for individuals with diverse needs. 
APPENDIX A

THE INFORMED CONSENT FORM FOR

THE FIRST PART OF THE STUDY 


\section{Informed Consent}

I agree to participate in this research study conducted by Ms. Kuei-an Kan, a doctoral student at the University of North Texas. I understand the purpose of this study is to examine the effects of dream interpretation. I also understand that I will be asked to fill out a self-evaluation questionnaire.

I know that my participation is voluntary. I can withdraw from the study at any time. I know that I am free not to share my experiences or answer any question at any time of the study. I have been assured of the confidentiality of my personal information and my experiences with and responses to the study. Any question I have concerning the study will be answered anytime before, during or after the study.

I understand that this study has been approved by the Committee for the Protection of Human Subjects at the University of North Texas, telephone number (940) 565-3940. I also understand that I may contact Dr. Janice Holden at the University of North Texas, Department of Counseling, Development, and Higher Education, Stovall Hall room 155, telephone number (940) 565-2919 if I have any question or concern about this study.

Participant

Researcher
Date

Date 
APRENDIX B

THE INFORMED CONSENT FORM FOR

THE SECOND PART OF THE STUDY 


\section{Informed Consent}

I agree to participate in this research study conducted by Ms. Kuei-an Kan, a doctoral student at the University of North Texas. I understand the purpose of this study is to examine the effects of dream interpretation. I also understand that I will be asked to participate in a guided dream interpretation session, a structured interview, and fill out self-evaluation questionnaires.

I understand the benefits and the risks involved in participating in this study. I know that my participation is voluntary. I can withdraw from the study at any time. I know that I am free not to share my experiences or answer any question at any time of the study. I have been assured of the confidentiality of my personal information and my experiences with and responses to the study. Any question I have concerning the study will be answered anytime before, during, or after the study.

I understand that this study has been approved by the Committee for the Protection of Human Subjects at the University of North Texas, telephone number (940) 565-3940. I also understand that I may contact Dr. Janice Holden at the University of North Texas, Department of Counseling, Development, and Higher Education, Stovall Hall room 155, telephone number (940) 565-2919 if I have any question or concern about this study.

Participant

Researcher
Date

Date 
APPENDIX C

MAJOR EFFECTS OF FOCUSING-ORIENTED

DREAM INTERPRETATION 


\section{Major Effects of Focusing-Oriented Dream Interpretation}

1) a sense of easing or release of tension associated with the dream

(1) (+) When I think of the meaning of the dream I feel relaxed.

(2) $(+)$ I experience a sense of easing associated with the meaning of the dream.

(3) (+) When I think of the meaning of the dream I feel calm and peaceful.

(4) (-) I feel somewhat restless and ill at ease when I think of the meaning of the dream.

(5) (-) I experience a sense of uneasiness associated with the meaning of the dream.

(6) (-) When I think of the meaning of the dream I experience some tension.

2) a sense of fresh air or increase of positive energy associated with the dream

(7) (+) I experience a sense of positive energy flowing when I think of the meaning of the dream.

(8) (+) I experience a sense of fresh air associated with the meaning of the dream.

(9) (+) I feel somewhat energized when I think of the meaning of the dream.

$(10)(+)$ I feel inspired and full of energy when I think of the meaning of the dream.

(11) (-) I feel low in energy when I think of the meaning of the dream.

(12) (-) When I think of the meaning of the dream I feel somewhat stifled.

(13) (-) I feel a lack of energy when I think of the meaning of the dream.

(14) (-) When I think of the meaning of the dream I feel lethargic.

3) increased self understanding

(15) ( + I have a new understanding of myself as a result of the process.

$(16)(+)$ The process facilitated self understanding.

$(17)(+)$ I see an aspect of myself differently because of the process.

(18) $(+)$ As a result of the process I have new insight.

(19) (-) The process did not change my understanding of myself in any way.

(20) (-) No new awareness of myself came from the process.

(21) (-) My knowledge of myself is completely unchanged in spite of the process.

4) a sense of movement, reconciliation, or healing

(22) $(+)$ I experienced a sense of reconciliation with a concern.

(23) $(+)$ The process helped facilitate some movement toward resolution of a concern. 
(24) $(+)$ There is a sense of experiencing or seeing things differently because of the process.

$(25)(+)$ I experienced some healing.

(26) (+) I experienced a sense of having worked through something.

(27) (-) No sense of transformation took place in the process.

(28) (-) The process resulted in no personal change or transformation.

(29) (-) I feel exactly like I felt before

5) development of a new step or new direction regarding a concern

(30) $(+)$ The process provided me with a new step or new direction.

(31) $(+)$ I found different ways of handling a concern.

(32) (+) A next step came to me in the process.

(33) (+) A sense of new opening or possibility emerged out of the process.

(34) (-) I feel I got no new ideas for ways of dealing with people or problems.

(35) (-) The process did not show me what to do next.

(36) (-) I did not see new ways to make things in my life different.

6) enhanced valuation of dreams

(37) (+) Dreams are meaningful.

(38) $(+)$ Dreams carry significant messages from aspects of ourselves or the universe that are often unavailable to us when we are awake.

(39) (+) Dreams have a lot to offer.

(40) (+) Dreams can be helpful to the dreamer.

(41) (+) Dreams are valuable.

(42) (-) Dreams are insignificant.

(43) (-) Dreams are meaningless left over brain activities from the day.

(44) (-) I see no value in dreams.

(45) (-) I gain nothing from my dreams.

7) enhanced understanding of the meaning of the dream

(46) (+) I have a better understanding of the meaning of the dream because of the process.

(47) (+) The process was important to my understanding of the dream.

(48) $(+)$ The process helped facilitate understanding of the dream.

(49) (+) I experienced a deeper understanding of the dream.

(50) (-) The process was not beneficial to my understanding of the dream.

(51) (-) My understanding of the meaning of the dream stayed the same.

(52) (-) I gained no new understanding of the meaning of the dream. 
APPENDIX D

RANDOM ITEM ASSIGNMENT FOR PART ONE PILOT FORM 


\section{$\underline{\text { Random Item Assignment for Part One Pilot Form }}$}

1428: row 14 column 28 . moved vertically down column

\begin{tabular}{|c|c|c|c|}
\hline $\begin{array}{l}\text { Original Form } \\
\text { Item No. }\end{array}$ & $\begin{array}{l}\text { Pilot Form } \\
\text { Item No. }\end{array}$ & $\begin{array}{l}\text { Original Form } \\
\text { Item No. }\end{array}$ & $\begin{array}{l}\text { Pilot Form } \\
\text { Item No. }\end{array}$ \\
\hline 1. & 41. & 27 . & 38. \\
\hline 2 . & 9. & 28 & 35. \\
\hline 3. & 47. & 29. & 27. \\
\hline 4. & 1. & 30. & 8 \\
\hline 5. & 4 & 31. & 17. \\
\hline 6. & 48 & 32. & 36. \\
\hline 7. & 3 & 33. & 10. \\
\hline 8. & 44. & 34. & 15. \\
\hline 9. & 28 & 35. & 42 \\
\hline 10. & 52. & 36. & 11. \\
\hline 11. & 19. & 37. & 31. \\
\hline 12. & 22. & 38. & 26. \\
\hline 13. & 24 . & 39. & 46 \\
\hline 14. & 23. & 40. & 43. \\
\hline 15. & 13. & 41 . & 50. \\
\hline 16. & 6. & 42 . & 30. \\
\hline 17. & 18. & 43. & 45. \\
\hline 18. & 2. & 44 & 25 \\
\hline 19. & 12. & 45. & 7. \\
\hline 20 & 5. & 46. & 39. \\
\hline 21. & 21. & 47 & 29. \\
\hline 22. & 32. & 48 & 34. \\
\hline 23. & 33. & 49. & 14. \\
\hline 24 & 40. & 50. & 49 \\
\hline 25 & 16. & 51. & 51. \\
\hline 26 & 37. & 52. & 20 \\
\hline
\end{tabular}

(Kerlinger, 1986, Appendix C: Random numbers and statistics) 


\section{APPENDIX $\mathrm{E}$ \\ PILOT PART ONE OF THE DREAM INTERPRETATION \\ EFFECTS QUESTIONNAIRE}




\section{$\underline{\text { Part One }}$}

Following is a list of statements that have been used to determine the results of dream interpretation. Please read each item and rate them from 0 to 6 depending on how much the statement applies to you at this point. For example, if a statement is "not at all like you" or "does not describe your experience at all", circle a " 0 ". If a statement is "very much like you" or "describes your experience very much", circle a "6". If a statement applies somewhere in between, circle either the "1", "2", "3", "4", or "5" whichever applies to you. There are no "right" or "wrong" answers because each person's experience is somewhat different. Please make your decisions on the basis of your experience at this point.

not at all very much like me like me

0---1---2---3---4---5---6 1. I feel somewhat restless and ill at ease when I think of the dream.

$0---1---2---3---4---5---6 \quad 2$. As a result of the process I have new insight.

0---1---2---3---4---5---6 3. I experience a sense of positive energy flowing when I think of the meaning of the dream.

0---1---2---3---4---5---6 4. I experience a sense of uneasiness associated with the meaning of the dream.

0---1---2---3---4---5---6 5. No new awareness of myself came from the process.

0---1---2---3---4---5---6 6. The process facilitated self understanding.

0---1---2---3---4---5---6 7. I gain nothing from my dreams.

0---1---2---3---4---5---6 8. The process provided me with a new step or new direction.

0---1---2---3---4---5---6 9. I experience a sense of easing associated with the meaning of the dream.

0---1---2---3---4---5---6 10. A sense of new opening or possibility emerged out of the process. 
not at all very much

like me like me

0---1---2---3---4---5---6 11. I did not see new ways to make things in my life different.

0--1---2---3---4---5---6 12. The process did not change my understanding of myself in any way.

0---1---2---3---4---5---6 13. I have a new understanding of myself as a result of the process.

0---1---2---3---4---5---6 14. I experienced a deeper understanding of the dream.

0---1---2---3---4---5---6 15. I feel I got no new ideas for ways of dealing with people or problems.

0---1---2---3---4----5---6 16. I experienced some healing.

0--1---2---3---4---5---6 17. I found different ways of handling a concern.

$0--1---2---3--4---5--6 \quad 18$. I see an aspect of myself differently because of the process.

0--1---2---3---4---5---6 19. I feel low in energy when I think of the meaning of the dream.

0---1---2---3---4---5---6 20. I gained no new understanding of the meaning of the dream.

0---1---2---3---4---5---6 21. My knowledge of myself is completely unchanged in spite of the process.

$0---1---2---3---4---5---6 \quad 22$. When I think of the meaning of the dream I feel somewhat stifled.

0--1---2---3---4---5---6 23. When I think of the meaning of the dream I feel lethargic.

$0--1---2---3---4---5--6 \quad 24$. I feel a lack of energy when I think of the meaning of the dream.

0---1---2---3---4---5---6 25. I see no value in dreams.

0---1---2---3---4---5---6 26. Dreams carry significant messages from aspects of ourselves or the universe that are often unavailable to us when we are awake. 
not at all very much

like me like me

0---1---2---3---4---5---6 27. I feel exactly like I felt before

0---1---2---3---4---5---6 28. 1 feel somewhat energized when I think of the meaning of the dream.

0---1---2---3---4---5---6 29. The process was important to my understanding of the dream.

$0---1---2---3---4---5---6 \quad 30$. Dreams are insignificant.

0---1---2---3---4---5---6 31. Dreams are meaningful.

0---1---2---3---4---5---6 32. I experienced a sense of reconciliation with a concern.

0--1---2---3---4---5---6 33. The process helped facilitate some movement toward resolution of a concern.

0---1---2---3---4---5---6 34. The process helped facilitate understanding of the dream.

0---1---2---3---4---5---6 35. The process resulted in no personal change or transformation.

0---1---2---3---4---5---6 36. A next step came to me in the process.

0---1---2---3---4---5---6 37. I experienced a sense of having worked through something.

0---1---2---3---4---5---6 38. No sense of transformation took place in the process.

0---1---2---3---4---5---6 39. I have a better understanding of the meaning of the dream because of the process.

0---1---2---3---4---5---6 40. There is a sense of experiencing or seeing things differently because of the process.

$0--1---2---3---4---5---6 \quad 41$. When I think of the meaning of the dream I feel relaxed.

0---1---2---3---4---5---6 42. The process did not show me what to do next.

0---1---2---3---4---5---6 43. Dreams can be helpful to the dreamer.

0---1---2---3---4---5---6 44. I experience a sense of fresh air associated with the meaning of the dream. 
not at all very much

like me like me

0---1---2---3---4---5---6 45. Dreams are meaningless left over brain activities from the day.

0---1---2---3---4---5---6 46. Dreams have a lot to offer.

$0--1---2---3---4--5---6 \quad 47$. When I think of the meaning of the dream I feel calm and peaceful.

0---1---2---3---4---5---6 48. When I think of the meaning of the dream I experience some tension.

0---1---2---3---4---5---6 49. The process was not beneficial to my understanding of the dream.

0---1---2---3---4---5---6 50. Dreams are valuable.

0---1---2---3---4---5---6 51. My understanding of the meaning of the dream stayed the same.

0---1---2---3---4---5---6 52. I feel inspired and full of energy when I think of the meaning of the dream. 
APPENDIX $\mathrm{F}$

THE DREAM INTERPRETATION EFFECTS QUESTIONNAIRE

$\ldots$ 


\section{The Dream Interpretation Effects Questionnaire}

\section{Cover Page}

Following is a list of questions that will be used to gather your personal background information and information regarding your experience with this study.

Please read each item and answer it to the best of your knowledge. Please answer it as thoroughly as possible. However, you are free not to answer any question that seems intrusive to your privacy.

1) Gender: (a) Male (b) Female

2) Age: (a) 20's (b) 30's (c) 40's (d) 50's (d) 60's (e) Other (describe):

3) Marital status: (a) Single (b) Married (c) Separated (d) Divorced (e) Other (describe):

4) Education level: (a) Grade school (b) High School (c) Undergraduate (d) Graduate

5) Ethnic group: (a) African or African-American (b) Asian or Asian-American

(c) European or European American (d) Hispanic or Hispanic-American

(e) Other (describe):

6) How often do you remember your dreams?

7) How many dreams do you usually remember on a typical night?

8) Do you have any recurrent dreams?

(a) Yes (b) No (please circle one)

9) Do you have any nightmares?

(a) Yes (b) No (please circle one)

10) Have you had any previous experience of using an existing model to interpret your dream?

10

Yes No (please circle one) 
If the answer is yes, what was the model?

What was the experience for you? not helpful helpful

$$
\begin{array}{ccccccc}
0 & 1 & 2 & 3 & 4 & 5 & 6 \\
x----x----x----x & ----x----x----x
\end{array}
$$

11) How helpful do you expect the following process of dream interpretation to be? not helpful

$$
\begin{array}{lllllll}
0 & 1 & 2 & 3 & 4 & 5 & 6 \\
x----x----x----x----x----x & ---x
\end{array}
$$

What is your expectation (if any)?

12) How would you rate the length of the dream you have chose to work on today? very short very long

$$
\begin{array}{ccccccc}
0 & 1 & 2 & 3 & 4 & 5 & 6 \\
x----x---x & ---x----x & ---x &
\end{array}
$$




\section{Part One}

Following is a list of statements that have been used to determine the results of dream interpretation. Please read each item and rate them from 0 to 6 depending on how much the statement applies to you at this point. For example, if a statement is "not at all like you" or "does not describe your experience at all", circle a " 0 ". If a statement is "very much like you" or "describes your experience very much", circle a "6". If a statement applies somewhere in between, circle either the "1", "2", "3", "4", or "5" whichever applies to you. There are no "right" or "wrong" answers because each person's experience is somewhat different. Please make your decisions on the basis of your experience at this point.

not at all very much like me like me

0---1---2---3---4---5---6 1. I feel somewhat restless and ill at ease when I think of the dream.

$0---1---2---3---4---5---6 \quad 2$. As a result of the process I have new insight.

$0---1---2---3---4---5---6 \quad 3$. I experience a sense of positive energy flowing when I think of the meaning of the dream.

0---1---2---3---4---5---6 4. I experience a sense of uneasiness associated with the meaning of the dream.

$0--1---2---3---4---5---6 \quad 5$. No new awareness of myself came from the process.

$0---1---2---3---4---5---6 \quad 6$. The process facilitated self understanding.

0---1---2---3---4---5---6 7. I gain nothing from my dreams.

0---1---2---3---4---5---6 8. The process provided me with a new step or new direction.

0---1---2---3---4---5---6 9. I experience a sense of easing associated with the meaning of the dream.

0---1---2---3---4---5---6 10. A sense of new opening or possibility emerged out of the process. 
not at all very much

like me like me

0---1 ---2---3---4---5--6 11. I did not see new ways to make things in my life different.

$0---1---2---3---4---5--6 \quad 12$. The process did not change my understanding of myself in any way.

0---1---2---3---4---5---6 13. I have a new understanding of myself as a result of the process.

0---1---2---3---4---5---6 14. I experienced a deeper understanding of the dream.

0---1---2---3---4---5---6 15. I feel I got no new ideas for ways of dealing with people or problems.

0---1---2---3---4---5---6 16. I experienced some healing.

0---1---2---3---4---5---6 17 . I found different ways of handling a concern.

$0---1--2---3---4---5---6 \quad 18$. I see an aspect of myself differently because of the process.

0---1---2---3---4---5---6 19. I feel low in energy when I think of the meaning of the dream.

$0--1---2---3---4---5---6 \quad 20$. I gained no new understanding of the meaning of the dream.

0---1---2---3---4---5---6 21. My knowledge of myself is completely unchanged in spite of the process.

$0--1---2---3--4---5---6 \quad 22$. When I think of the meaning of the dream I feel somewhat stifled.

0--1---2---3---4---5---6 23. When I think of the meaning of the dream I feel lethargic.

$0--1---2---3---4---5--6 \quad 24$. I feel a lack of energy when I think of the meaning of the dream.

0---1---2---3---4---5---6 25. I see no value in dreams.

0---1---2---3---4---5---6 26. Dreams carry significant messages from aspects of ourselves or the universe that are often unavailable to us when we are awake. 
not at all very much

like me like me

0---1---2---3---4---5---6 27. I feel exactly like I felt before

0---1---2---3---4---5---6 28. I feel somewhat energized when I think of the meaning of the dream.

$0---1---2---3---4---5---6 \quad 29$. The process was important to my understanding of the dream.

0---1---2---3---4---5---6 30. Dreams are insignificant.

0---1---2---3---4---5---6 31. Dreams are meaningful.

$0---1---2---3---4---5---6 \quad 32$. I experienced a sense of reconciliation with a concern.

$0--1---2---3---4---5---6 \quad 33$. The process helped facilitate some movement toward resolution of a concern.

0---1---2---3---4---5---6 34. The process helped facilitate understanding of the dream.

0---1---2---3---4---5---6 35. The process resulted in no personal change or transformation.

0---1---2---3---4---5---6 36. A next step came to me in the process.

0---1---2---3---4---5---6 37. I experienced a sense of having worked through something.

0---1---2---3---4---5---6 38. No sense of transformation took place in the process.

$0--1---2---3---4---5---6 \quad 39$. I have a better understanding of the meaning of the dream because of the process.

$0---1---2---3---4---5---6 \quad 40$. There is a sense of experiencing or seeing things differently because of the process.

$0--1---2---3---4--5--6 \quad 41$. When I think of the meaning of the dream I feel relaxed.

0---1---2---3---4---5---6 42. The process did not show me what to do next.

0---1---2---3---4---5---6 43. Dreams can be helpful to the dreamer.

0---1---2---3---4---5---6 44. I experience a sense of fresh air associated with the meaning of the dream. 
not at all very much

like me like me

0---1---2---3---4---5---6 45. Dreams are meaningless left over brain activities from the day.

0---1---2---3---4---5---6 46. Dreams have a lot to offer.

$0--1---2---3---4---5---6 \quad 47$. When I think of the meaning of the dream I feel calm and peaceful.

0---1---2---3---4---5---6 48. When I think of the meaning of the dream I experience some tension.

0---1---2---3---4---5---6 49. The process was not beneficial to my understanding of the dream.

0---1---2---3---4---5---6 50. Dreams are valuable.

0---1---2---3---4---5---6 51. My understanding of the meaning of the dream stayed the same.

$0--1---2---3---4---5---6 \quad 52.1$ feel inspired and full of energy when I think of the meaning of the dream. 
Part Two

Following is another list of statements that have been used to describe the experience of dream work. Please read each item and rate them from 0 to 6 depending on how much the statement applies to you at this point. You are encouraged to answer the questions on the basis of your experience, not what you think it should have been. Please answer it as thoroughly as possible. However, you are free not to answer any question that seems intrusive to your privacy.

1) To what extent was the process helpful in facilitating your understanding of the meaning of the dream?

not at all

$$
\begin{array}{ccccccc}
0 & 1 & 2 & 3 & 4 & 5 & 6 \\
x----x----x & ---x & ----x----x----x
\end{array}
$$

If you consider the process helpful, please describe in what way it was helpful for you in 3-5 sentences.

2) What is the meaning of the dream as you perceive it at this point? (Please describe it in 3-5 sentences.)

*Keep this meaning in mind as you answer the following questions:

3) How does it feel in your body when you think of the meaning of the dream?

*If you find it difficult to come up with your own description, you can answer the question by describing the sensation associate with your body, which may include the upper part of your body (head, face, neck and shoulder), the middle part of your body (chest, abdomen, upper and lower back, arms and hands), and the lower part of your body (legs and feet) 
4) To what extent did the dream remind you of a concern in your current waking life? not at all

$\begin{array}{lllllll}0 & 1 & 2 & 3 & 4 & 5 & 6 \\ \mathrm{x}----\mathrm{x}----\mathrm{x}----\mathrm{x}----\mathrm{x}----\mathrm{x}----\mathrm{x}\end{array}$

What is (are) the concern(s)?

5) To what extent did the process help facilitate some movement toward resolution of the current concern mentioned above?

not at all

to a great extent

$$
\begin{aligned}
& \begin{array}{lllllll}
0 & 1 & 2 & 3 & 4 & 5 & 6
\end{array} \\
& \text { X----X----X----X----X----X----X }
\end{aligned}
$$

6) To what extent did the dream remind you of an unresolved issue from the past?

not at all to a great extent

$$
\begin{array}{lllllll}
0 & 1 & 2 & 3 & 4 & 5 & 6 \\
\mathrm{X}----\mathrm{X}----\mathrm{X}-\mathrm{-}--\mathrm{X}----\mathrm{X}----\mathrm{X}----\mathrm{X}
\end{array}
$$

What is (are) the issue(s)?

7) To what extent did the process help facilitate some movement toward resolution of the past issue mentioned above?

$$
\text { no resolution complete resolution }
$$

$$
\begin{aligned}
& \begin{array}{lllllll}
0 & 1 & 2 & 3 & 4 & 5 & 6
\end{array} \\
& \text { X----X----X-----X----X----X----X }
\end{aligned}
$$

8) Did the process remind you of an aspect(s) of yourself that you were already aware of but did not accept?

$$
10
$$

Yes No (please circle one)

What is that aspect of yourself?

How accepting do you feel of this aspect now?

$$
\begin{aligned}
& \text { no acceptance } \\
& \begin{array}{lllllll}
0 & 1 & 2 & 3 & 4 & 5 & 6
\end{array} \\
& \text { X----X----X----X----X----X----X }
\end{aligned}
$$


9) Did the process help you identify an aspect(s) of yourself that you were not aware of before?

$$
\begin{array}{cc}
1 & 0 \\
\text { Yes } & \text { No (please circle one) }
\end{array}
$$

What is that aspect of yourself?

How accepting do you feel of this aspect now?

$$
\begin{aligned}
& \text { no acceptance total acceptance } \\
& \begin{array}{lllllll}
0 & 1 & 2 & 3 & 4 & 5 & 6
\end{array}
\end{aligned}
$$

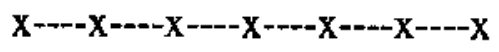

10) To what extent did the process help you identify a quality(s) of yourself that you would like to have more of?

not at all

$$
\begin{array}{ccccccc}
0 & 1 & 2 & 3 & 4 & 5 & 6 \\
x----x---x---x---x---x---x
\end{array}
$$

Please describe the quality(s) that you would like to have more of.

11) To what extent did the process help you identify a quality(s) of yourself that you would like to have less of?

$$
\begin{aligned}
& \text { not at all to a great extent } \\
& \begin{array}{lllllll}
0 & 1 & 2 & 3 & 4 & 5 & 6
\end{array} \\
& \mathrm{x}-\mathrm{-}-\mathrm{x}-\mathrm{-}-\mathrm{-}-\mathrm{x}-\mathrm{-}-\mathrm{x}-\mathrm{-}-\mathrm{-}-\mathrm{x}----\mathrm{x}-\mathrm{-}-\mathrm{x}
\end{aligned}
$$

Please describe the quality(s) that you would like to have less of.

12) To what extent did the dream reflect an unfulfilled wish(es)?

not at all

$$
\begin{array}{ccccccc}
0 & 1 & 2 & 3 & 4 & 5 & 6 \\
x---x----x & ----x----x & ----x---x
\end{array}
$$

Please describe the wish the dream reflected. 
13) To what extent did the dream reflect what you are feeling or doing about sexuality? not at all to a great extent

$\begin{array}{lllllll}0 & 1 & 2 & 3 & 4 & 5 & 6 \\ x----x---\cdot x----x----x----x----x\end{array}$

Please describe the sexual aspect the dream reflected.

14) To what extent did the dream reflect spiritual aspect(s) or potential in you? not at all

$$
\begin{array}{ccccccc}
0 & 1 & 2 & 3 & 4 & 5 & 6 \\
X----x----X---x & ----x---x---x
\end{array}
$$

Please describe the spiritual aspect the dream reflected.

15) To what extent did the process help you see the value of something rejected or devalued in your life?

not at all

$$
\begin{aligned}
& \begin{array}{lllllll}
0 & 1 & 2 & 3 & 4 & 5 & 6
\end{array}
\end{aligned}
$$

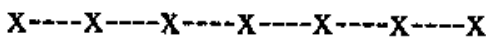

Please describe.

16) To what extent did the process help you experience healing or reconciliation from a current or past psychological wound?

not at all

$$
\begin{array}{ccccccc}
0 & 1 & 2 & 3 & 4 & 5 & 6 \\
x----X----x & ----X & ---x & ----X & ---x
\end{array}
$$

Please describe.

17) To what extent did you see your dream as expanding your view of self, others, or the world?

not at all

$$
\begin{array}{lllllll}
0 & 1 & 2 & 3 & 4 & 5 & 6
\end{array}
$$

Please describe. 
18) To what extent did the process provide you with new step or new direction to your life?

not at all

$$
\begin{aligned}
& \begin{array}{lllllll}
0 & 1 & 2 & 3 & 4 & 5 & 6
\end{array}
\end{aligned}
$$

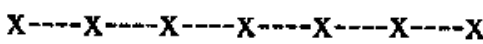

What is the new step or direction (if any)?

19) To what extent did the process change the way you see yourself or a concern. not at all to a great extent

$$
\begin{array}{ccccccc}
0 & 1 & 2 & 3 & 4 & 5 & 6 \\
x---x & ---x & ---x & ---x & ---x & ---x
\end{array}
$$

Please describe the change (if any).

20) How creative do you find the dream to be at this point?

$$
\begin{aligned}
& \text { not creative very creative } \\
& \begin{array}{lllllll}
0 & 1 & 2 & 3 & 4 & 5 & 6
\end{array} \\
& \text { X----X----X----X-----X----X-----X }
\end{aligned}
$$

21) How obvious is the meaning of the dream to you at this point?

$$
\begin{aligned}
& \text { not at all } \\
& \begin{array}{lllllll}
0 & 1 & 2 & 3 & 4 & 5 & 6
\end{array} \\
& \text { X----X----X-----X----X----X----x }
\end{aligned}
$$

22) The process helped you discover meanings on the following levels at this point

(Check all that apply and describe the meaning):
(1) intrapersonal (issues or concerns within yourself)

(2) interpersonal (issues or concerns between yourself and others)

(3) spiritual

(4) sexual

(5) past issues or concerns

(6) present issues or concerns

(7) future issues or concerns

(8) other (describe it:

(9) none

Please describe the meaning. 
23) To what extent are you certain about the meaning of the dream you work on at this point?

not at all to a great extent

Why?

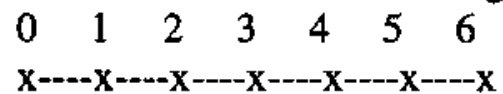

24) How would you categorize your dream at this point? (check all that apply)

(1) bizarre dream or strange dream

(2) scary dream or nightmare

(3) pleasant dream

(4) recurrent dream

(5) somatic or illness related dream

(6) sexual dream

(7) mundane dream

(8) spiritual or mystical dream

(9) problem solving type of dream

(10) intuitive or precognitive dream

(11) other (describe it: 
Part Three (for Oe2)

1) Do you notice any difference in the way you categorized the meaning of your dream before and after the dream interpretation process? (You can refresh your memory on your previous responses in part two of this questionnaire, item 22.)

\section{0}

Yes No (please circle one)

If yes, what is the difference?

2) To what extent did the meaning of the dream differ before and after the dream interpretation process?

no difference totally different

$$
\begin{array}{ccccccc}
0 & 1 & 2 & 3 & 4 & 5 & 6 \\
x----x---x---x-x---x---x---x
\end{array}
$$

What is the difference (if any)?

3) How much did the process change the way you feel about the value of dreams in general at this point?

not at all

$$
\begin{array}{ccccccc}
0 & 1 & 2 & 3 & 4 & 5 & 6 \\
x----x---x----x & ---x----x & ----x
\end{array}
$$

If yes, in what way?

4) How helpful was the process of dream interpretation?

not helpful very helpful

$$
\begin{array}{ccccccc}
0 & 1 & 2 & 3 & 4 & 5 & 6 \\
x----x----x & ----x & ----x----x---x
\end{array}
$$

If yes, in what way? 
5) To what extent was the process of dream interpretation as helpful as you expected? much less than about what much more than

I expected I expected I expected

$$
\begin{array}{lllllll}
0 & 1 & 2 & 3 & 4 & 5 & 6 \\
x---x----x---x---x----x
\end{array}
$$

6) How eager are you to use this form of dream interpretation in the future?

$$
\begin{aligned}
& \text { not at all } \\
& \begin{array}{lllllll}
0 & 1 & 2 & 3 & 4 & 5 & 6
\end{array}
\end{aligned}
$$

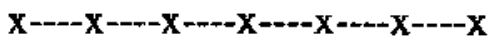

7) Do you notice any difference in the way you categorized your dream before and after the process of dream interpretation? (You can refresh your memory on your previous responses in part two of this questionnaire, item 24.)

10

If yes, why?

Yes No (please circle one) 
Part Three (for Oc2)

1) Do you notice any difference in the way you categorized the meaning of your dream before and after the 45-minute process? (You can refresh your memory on your previous responses in part two of this questionnaire, item 22.)

10

Yes No (please circle one)

If the answer is yes, what is the difference?

2) To what extent did the meaning of the dream differ before and after the 45 -minute process? no difference totally different

$\begin{array}{lllllll}0 & 1 & 2 & 3 & 4 & 5 & 6\end{array}$

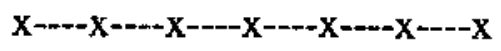

What is the difference (if any)?

3) How much did the process change the way you feel about the value of dreams in general at this point?

not at all a great deal

$\begin{array}{lllllll}0 & 1 & 2 & 3 & 4 & 5 & 6\end{array}$

x----x----x----x----x----x----x

If yes, in what way?

4) How helpful was the 45-minute process?

not helpful very helpful

$\begin{array}{lllllll}0 & 1 & 2 & 3 & 4 & 5 & 6\end{array}$

If yes, in what way?

x----x----X----x----x----x----x 
7) Do you notice any difference in the way you categorized your dream before and after the 45-minute process? (You can refresh your memory on your previous responses in part two of this questionnaire, item 24.)

$$
10
$$

Yes No (please circle one)

If yes, why? 
Part Three (for Oc3)

1) Do you notice any difference in the way you categorized the meaning of your dream in the beginning, after the 45-minute process, and after the dream interpretation process? (You can refresh your memory on your previous responses in part two of this questionnaire, item 22.)

10

Yes No (please circle one)

If the answer is yes, what is the difference?

2) To what extent did the meaning of the dream differ in the beginning, after the 45minute process, and after the dream interpretation process? no difference totally different

$$
\begin{array}{ccccccc}
0 & 1 & 2 & 3 & 4 & 5 & 6 \\
x----x---x---x---x---x---x
\end{array}
$$

What is the difference (if any)?

3) How much did the process change the way you feel about the value of dreams in general at this point?

not at all

$$
\begin{aligned}
& \begin{array}{lllllll}
0 & 1 & 2 & 3 & 4 & 5 & 6
\end{array}
\end{aligned}
$$

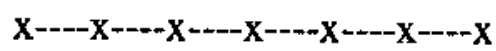

If yes, in what way?

4) How helpful was the process of dream interpretation?

$$
\text { not helpful very helpful }
$$

$$
\begin{aligned}
& \begin{array}{lllllll}
0 & 1 & 2 & 3 & 4 & 5 & 6
\end{array}
\end{aligned}
$$

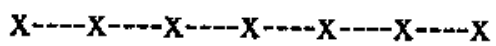

If yes, in what way? 
5) To what extent was the process of dream interpretation as helpful as you expected? much less than about what much more than I expected I expected I expected

$$
\begin{array}{lllllll}
0 & 1 & 2 & 3 & 4 & 5 & 6 \\
x----X----x----X----X-\cdots--X----X
\end{array}
$$

6) How eager are you to use this form of dream interpretation in the future? not at all

$$
\begin{array}{ccccccc}
0 & 1 & 2 & 3 & 4 & 5 & 6 \\
x----x---x----x----x & ---x----x
\end{array}
$$

7) Do you notice any difference in the way you categorized your dream in the beginning, after the 45-minute process, and after the process of dream interpretation? (You can refresh your memory on your previous responses in part two of this questionnaire, item 24.)

$$
10
$$

Yes No (please circle one)

If yes, why? 
APPENDIX G

STRUCTURED INTERVIEW 


\section{$\underline{\text { Structured Interview }}$}

1) Do you have any question concerning the above process?

2) Do you have any comment you would like to make at this time?

3) Is there anything you gained from the dream work that was not covered by the above process?

4) Now that we are about to finish, how are you feeling overall? 


\section{REFERENCES}

Antrobus, J. S. (1993). Dreaming: Can we do without it? In A. Moffitt, M. Kramer, \& R. Hoffman (Eds.), The functions of dreaming (pp. 549-558). Albany, NY: State University of New York.

Aserinsky, E., \& Kleitman, N. (1953). Regularly occurring periods of eye motility, and concomitant phenomena during sleep. Science, 118, 273-274.

Buchholz, M. B. (1990). Using dreams in family therapy. Journal of Family Therapy, 12, 387-396.

Bynum, E. B. (1980). The use of areams in family therapy. Psychotherapy: Theory, Research, and Practice, 17, $227-231$.

Campbell, P., \& McMahon, E. (1985). Bio-spirituality: Focusing as a way to grow. Chicago: Loyola University.

Cartwright, R. D. (1977). Night life: Explorations in dreaming. Englewood Cliffs, NJ: Prentice Hall.

Cartwright, R. D., Tipton, L. W., \& Wicklund, J. (1980). Focusing on dreams: A preparation program for psychotherapy. Archives of General Psychiatry, 37, 275-277.

Cartwright, R. D., \& Lamberg, L. (1992). Crisis 
dreaming: Using your dreams to solve your problems. New York: HarperCollins.

Cogar, M. C., \& Hill, C. E. (1992). Examining the effects of brief individual dream interpretation. Dreaming, 2, $239-248$.

Cornell, A. W. (1996). The power of focusing: A practical guide to emotional self-healing. Oakiand, CA: New Harbinger.

Crick, F., \& Mitchison, G. (1983). The function of dream sleep. Nature, 304, 111-114.

Crick, F., \& Mitchison, G. (1986). REM sleep and neural nets. Journal of Mind and Behavior, 7, 229-249. Cronbach, L. J. (1951). Coefficient alpha and the internal structure of tests. Psychometrika, 16, 297-331.

Diemer, R. A., Lobell, L. K., Vivino, B. L., \& Hill, C. E. (1996). Comparison of dream interpretation, event interpretation, and unstructured sessions in brief therapy. Journal of Counseling Psychology, 43, 99-112.

Domhoff, G. W. (1993). The repetition of dreams and aream elements: A possible clue to the function of dreams. In A. Moffitt, M. Kramer, \& R. Hoffman (Eds.), The functions of dreaming (pp. 293-320). Albany, NY: State University of New York. 
Don, N. S. (1977-78). The transformation of conscious experience and its EEG correlates. Journal of Altered States of Consciousness, 3, $147-168$.

Evans, C. (Ed.). (1983). Landscapes of the night: How and why we dream. Viking, NY: Peter Evans.

Falk, D. R., \& Hill, C. E. (1995). The effectiveness of dream interpretation groups for women undergoing a divorce transition. Dreaming, 5, 29-42.

Fantz, R. E. (1983). Gestalt approach. In J. L. Fosshage \& C. A. Loew (Eds.), Dream interpretation: A comparative approach (pp. 191-241). New York: PMA.

Faraday, A. (1972). Dream power. London: Hodder and Stoughton.

Faraday, A. (1974). The dream game. New York: Harper \& Row.

Foulkes, D. (1985), Dreaming: A cognitivepsychological analysis. Hillsdale, NJ: Lawrence Erlbaum. Foulkes, D. (1991). Why study dreaming: One researcher's perspective. Dreaming, 1, 245-248.

Foulkes, D., \& Vogel, F. (1965). Mental activity at sleep onset. Journal of Abnormal Psychology, 70, 231-243.

Foulkes, D., Spear, P. S., \& Symonds, J. D. (1966). Individual differences in mental activity at sleep onset. 
Journal of Abnormal Psychology, 71, 280-286.

Foulkes, D., \& Fleisher, S. (1975). Mental activity in relaxed wakefulness. Journal of Abnormal Psychology, 84, $66-75$.

Freud, S. $(1900 / 1952)$. On dreams. New York: W. W. Norton \& Co.

Freud, S. (1900/1966). The interpretation of dreams. New York: Avon.

Freud, S. (1935/1963). A general introduction to psychoanalysis. New York: Simon \& Shuster.

Garfield, P. (1989). Pathway to ecstasy: The way of the dream mandala. New York: Prentice Hall.

Gendlin, E. T. (1962). Experiencing and the creation of meaning: A philosophical and psychological approach to the subjective. New York: Macmillan.

Gendlin, E. T. (1969). Focusing. Psychotherapy: Theory, Research and Practice, 6, 4-15.

Gendlin, E. T. (1970). A short summary and some long predictions. In J. Hart and T. Tomlison (Eds.), New directions in client-centexed therapy (pp. 544-562). Boston: Houghton Mifflin.

Gendlin, E. T. (1974). Client-centered and experiential psychotherapy. In D. A. Wexler and L. N. Rice 
(Eds.), Innovations in client-centered therapy (pp. 211246). New York: Wiley-Interscience.

Gendlin, E. T. (1981). Focusing. New York: Bantam. Gendlin, E. T. (1986). What comes after traditional psychotherapy research. American Psychologist, 41, 131-136. Gendlin, E. T. (1986). Let your body interpret your dreams. Wilmette, IL: Chiron.

Gendlin, E. T. (1996). Focusing-oriented psychotherapy: A manual of the experiential method. New York: Guilford.

Gendlin, E. T., Beebe, J., Cassens, J., Klein, M., \& Oberlander, M. (1968). Focusing ability in psychotherapy, personality, and creativity. In J. M. Schlien (Ed.), Research in psychotherapy (Vol. 3, pp. 217-241). Washington, DC: American Psychological Association. Gray, J. P. (1977). The influence of experiential focusing on state anxiety and problem-solving (Doctoral dissertation, California School of Professional Psychology, 1976). Dissertation Abstracts International, $38,898$.

Greenberg, L. S., \& Higgins, H. M. (1980). Effects of two-chair dialogue and focusing on conflict resolution. Journal of Counseling Psychology, 27, 221-224.

Hall, J. A. (1983). Jungian dream interpretation. 
Toronto: Inner City Books.

Hart, J. (1970). The development of client-centered therapy. In J. Hart and T. Tomlinson (Eds.). New directions in client-centered therapy (pp. 3-22). Boston: Houghton Mifflin.

Hendricks, M. \& \& Cartwright, R. (1978). Experiencing level in dreams: An individual difference variable. Psychotherapy: Theory, Research and Practice, 15, 292-298. Hill, C. E. (1996). Working with dreams in psychotherapy. New York: Guilford.

Hil1, C. E., Diemer, R., Hess, S., Hillyer, A., \& Seeman, R. (1993). Are the effects of dream interpretation on session quality, insight, and emotions due to the dream itself, to projection, or to the interpretation process. Dreaming, 3, 269-280.

Hobson, J. A. (1988). The dreaming brain. New York: Basic.

Hobson, J. A. (1989). Sleep. New York: Scientific American.

Hunt, H. T. (1989). The multiplicity of dreams: Memory, imagination, and consciousness. New Haven, CT: Yale University.

Kantor, S., \& Zimring, F. M. (1976). The effects of 
focusing on a problem. Psychotherapy: Theory, Research and Practice, $13,255-258$.

Kerlinger, F. N. (1986). Foundations of behavioral research (3rd ed.). New York: Harcourt Brace Jovanovich College.

Klein, M. H., Mathieu-Coughlan, P., \& Kiesler, D. J. (1986). The experiencing Scales. In L. S. Greenberg and $W$. M. Pinsof (Eds.). The psychotherapeutic process: A research handbook (pp. 21-71). New York: Guilford.

Klein, J. (1995). Empathic felt sense listening and focusing: A workbook for learning and teaching. Chicago, IL: The Focusing Institute.

Kolb, G. E. (1979). Brief psychotherapy using dream interpretation. The American Journal of Psychoanalysis, 39 , $335-342$.

Levay, A. N., \& Weissberg, J. (1979). The role of dreams in sex therapy. Journal of Sex and Marital Therapy, $\underline{5}, 334-339$.

Loynes, J. L. (1985). Effects of experiential focusing on anger experiences of separated or divorced men (Doctoral dissertation, Michigan State University, 1984). Dissertation Abstracts International, 46, 963. Luborsky, L., Singer, B., \& Luborsky, L. (1975). 
Comparative studies of psychotherapies. Archives of General Psychiatry, 32, 995-1008.

Meier, C. A. (1987). The meaning and significance of dreams. Boston, MA: Sigo.

Melstrom, M. A., \& Cartwright, R. D. (1983). Effects of successful vs. unsuccessful psychotherapy outcome on some dream dimensions. Psychiatry, 46, 51-65.

Merrill, S., \& Cary, G. L. (1975). Dream analysis in brief psychotherapy. American Journal of Psychotherapy, 29, $185-193$.

Moffitt, A., Kramer, M., \& Hoffmann. (Eds.). (1993). The functions of dreaming. Albany, NY: State University of New York.

Norusis, M. J. (1994). SPSS for windows: Release 6.0. Chicago, IL: SPSS Inc.

Oberhoff, R. G. (1991). The role of attention in experiential focusing (Doctoral dissertation, University of Texas at Austin, 1990). Dissertation Abstracts Internationa1, 52, 505 .

Perls, F. (1969). Gestalt therapy verbatim. New York: Bantam.

Rogers, C. (1957). The necessary and sufficient conditions of therapeutic personality change. Journal of 
Consulting Psychology, 21, 95-103.

Rogers, C. (1958). A process conception of

psychotherapy. American Psychologist, 13, 142-149.

Rogers, C. (1967). The therapeutic relationship and

its impact: A study of psychotherapy with schizophrenics.

Madison, WI: University of Wisconsin.

Sanford, J. A. (1984). Dreams: God's forgotten

language. New York: Crossroad.

Shafton, A. (1995). Dream reader: Contemporary

approaches to the understanding of dreams. Albany, NY:

State University of New York.

Shuttleworth-Jordan, A. B., \& Saayman, G. S. (1989).

Differential effects of alternative strategies on

psychotherapeutic process in group dream work.

Psychotherapy, 26, 514-519.

States, B. O. (1992). The meaning of dreams. Dreaming, $\underline{2}, 249-262$.

Stevens, A. (1995). Private myths: Dreams and

dreaming. Cambridge, MA: Harvard University Press.

Strauch, I., \& Meier, B. (1996). In search of dreams:

Results of experimental dream research. Albany, NY: State University of New York.

Ullman, M. (1996). Appreciating dreams: A group 
approach. Thousand Oaks, CA: Sage.

VandenBos, G. R. (1974) An investigation of several methods of teaching Experiential Focusing (Doctoral dissertation, University of Detroit, 1973). Dissertation Abstracts International, 34, 5695.

Walker, A. M., Rablen, R. A., \& Rogers, C. (1960). Development of a scale to measure process change in psychotherapy. Journal of Clinical Psychology, 16, 79-85. Webb, D. E., \& Fagan, J. (1993). The impact of dream interpretation using psychological kinesiology on the frequency of recurring dreams. Psychotherapy and Psychosomatics, 59, 203-208.

Zimring, F. M., \& Balcombe, J. K. (1974). Cognitive operations in two measures of handling emotionally relevant material. Psychotherapy: Theory, Research and Practice, 11, $226-228$. 